\title{
Review \\ Probiotics, Prebiotics, and Phytogenic Substances for Optimizing Gut Health in Poultry
}

\author{
Awad A. Shehata ${ }^{1,2, *}$, Sakine Yalçın $\left.{ }^{3}{ }^{(}\right)$, Juan D. Latorre ${ }^{4}$, Shereen Basiouni ${ }^{5}$, Youssef A. Attia ${ }^{6}{ }^{(0)}$, \\ Amr Abd El-Wahab ${ }^{7,8} \oplus^{(}$, Christian Visscher ${ }^{7}{ }^{\circ}$, Hesham R. El-Seedi ${ }^{9,10,11}$, Claudia Huber ${ }^{12}{ }^{\circledR}$, Hafez M. Hafez ${ }^{13}$, \\ Wolfgang Eisenreich ${ }^{12}$ and Guillermo Tellez-Isaias $4, *$ (i)
}

Citation: Shehata, A.A.; Yalçın, S.; Latorre, J.D.; Basiouni, S.; Attia, Y.A.; Abd El-Wahab, A.; Visscher, C.;

El-Seedi, H.R.; Huber, C.; Hafez, H.M.; et al. Probiotics, Prebiotics, and Phytogenic Substances for Optimizing Gut Health in Poultry. Microorganisms 2022, 10, 395. https://doi.org/10.3390/ microorganisms10020395

Academic Editor: Claudio de Simone

Received: 15 December 2021 Accepted: 5 February 2022 Published: 8 February 2022

Publisher's Note: MDPI stays neutral with regard to jurisdictional claims in published maps and institutional affiliations.

Copyright: () 2022 by the authors Licensee MDPI, Basel, Switzerland. This article is an open access article distributed under the terms and conditions of the Creative Commons Attribution (CC BY) license (https:// creativecommons.org/licenses/by/ $4.0 /)$.
1 Research and Development Section, PerNaturam GmbH, 56290 Gödenroth, Germany

2 Avian and Rabbit Diseases Department, Faculty of Veterinary Medicine, University of Sadat City, Sadat City 32897, Egypt

3 Department of Animal Nutrition and Nutritional Diseases, Faculty of Veterinary Medicine, Ankara University (AU), 06110 Ankara, Turkey; sayalcin@ankara.edu.tr

4 Department of Poultry Science, University of Arkansas, Fayetteville, AR 72701, USA; j1115@uark.edu

5 Clinical Pathology Department, Faculty of Veterinary Medicine, Benha University, Benha 13518, Egypt; shereenbh@yahoo.com

6 Department of Agriculture, Faculty of Environmental Sciences, King Abdulaziz University, Jeddah 21589, Saudi Arabia; yaattia@kau.edu.sa

7 Institute for Animal Nutrition, University of Veterinary Medicine Hannover, 30173 Hannover, Germany; amrwahab5@mans.edu.eg (A.A.E.-W.); christian.visscher@tiho-hannover.de (C.V.)

8 Department of Nutrition and Nutritional Deficiency Diseases, Faculty of Veterinary Medicine, Mansoura University, Mansoura 35516, Egypt

9 Pharmacognosy Group, Biomedical Centre, Department of Pharmaceutical Biosciences, Uppsala University, SE 75124 Uppsala, Sweden; hesham.el-seedi@farmbio.uu.se

10 International Research Center for Food Nutrition and Safety, Jiangsu University, Zhenjiang 212013, China

11 International Joint Research Laboratory of Intelligent Agriculture and Agri-Products Processing, Jiangsu Education Department, Jiangsu University, Zhenjiang 212013, China

12 Bavarian NMR Center, Structural Membrane Biochemistry, Department of Chemistry, Technische Universität München, Lichtenbegstr. 4, 85748 Garching, Germany; claudia.huber@tum.de (C.H.); wolfgang.eisenreich@mytum.de (W.E.)

13 Institute of Poultry Diseases, Faculty of Veterinary Medicine, Free University of Berlin, 14163 Berlin, Germany; hafez.mohamed@fu-berlin.de

* Correspondence: awad.shehata@pernaturam.de (A.A.S.); gtellez@uark.edu (G.T.-I.)

Abstract: The gut microbiota has been designated as a hidden metabolic 'organ' because of its enormous impact on host metabolism, physiology, nutrition, and immune function. The connection between the intestinal microbiota and their respective host animals is dynamic and, in general, mutually beneficial. This complicated interaction is seen as a determinant of health and disease; thus, intestinal dysbiosis is linked with several metabolic diseases. Therefore, tractable strategies targeting the regulation of intestinal microbiota can control several diseases that are closely related to inflammatory and metabolic disorders. As a result, animal health and performance are improved. One of these strategies is related to dietary supplementation with prebiotics, probiotics, and phytogenic substances. These supplements exert their effects indirectly through manipulation of gut microbiota quality and improvement in intestinal epithelial barrier. Several phytogenic substances, such as berberine, resveratrol, curcumin, carvacrol, thymol, isoflavones and hydrolyzed fibers, have been identified as potential supplements that may also act as welcome means to reduce the usage of antibiotics in feedstock, including poultry farming, through manipulation of the gut microbiome. In addition, these compounds may improve the integrity of tight junctions by controlling tight junction-related proteins and inflammatory signaling pathways in the host animals. In this review, we discuss the role of probiotics, prebiotics, and phytogenic substances in optimizing gut function in poultry. 
Keywords: gut microbiota; dysbiosis; tight junctions; synbiotics; phytogenic substances; nutraceuticals; poultry; feed additives

\section{Introduction}

The permeability of the intestinal tract controls the uptake of nutrients and the transport of unwanted extracellular substances such as bacteria and xenobiotics, in addition to the non-digested substances. Therefore, gut health plays an essential role in the pathogenesis of various intestinal disorders. The permeability of the intestine is controlled by gut microbiota, digestive secretions, physical barriers (mucin, intestinal epithelial cells lining and tight junctions), and chemicals such as cytokines [1].

Under normal conditions, the symbiotic relationship between the gut microbiota and the host crucially determines intestinal health. However, a disturbance in the gut microbiota can lead to an imbalanced host-microbe relationship, which is called "dysbiosis" [2] Several factors, such as antinutritional factors in feed, heavy metals, toxic substances, bacterial toxins, herbicides, and antibiotics, can disrupt the gut microbiota. These impacts can lead to localized inflammation, extensive infection, or even intoxication [3-5], Additionally, the intestinal epithelium forms tight connections, acting as a biological barrier that controls the paracellular transit of different materials across the intestinal epithelium, including ions, solutes, and water. It also functions as a barrier of extracellular bacteria, antigens, and xenobiotics.

The impaired intestinal barrier function, commonly known as "leaky gut", is a condition in which the small intestine lining becomes damaged, leading to infiltration of luminal contents such as bacteria and their associated components including toxins to pass between epithelial cells. These conditions subsequently lead to cell damage and/or inflammation of the intestine, characterized by increased levels of bacteria-derived endotoxins in blood. This inflammatory process consumes significant amounts of nutrients, and, subsequently, has negative effects on metabolic responses, in particular on immunometabolic and endocrine responses. As a result, animal performances are severely reduced [6].

Additionally, field observations in Europe showed that the poultry industry faced several problems after the ban of antibiotic growth promoters (AGPs), including negative impacts on performance, animal welfare aspects, and general health issues [7]. In response to the AGP ban, several alternatives to antibiotics, such as probiotics, prebiotics, and phytogenic substances, have been developed, tested, evaluated, and used for chicken and turkey production at an increasing frequency [8]. In this review, we discuss the role of these alternatives in maintaining gut function through modulation of the gut microbiota and the related effects benefitting health and quality of poultry.

\section{Intestinal Microbiota in Poultry}

Microorganisms that live in animals' gastrointestinal tracts (GITs) are a prime example of beneficial bacteria [9]. Indeed, the GIT is the home of a diverse and plentiful microbial community providing essential functions to their host animals. Although the intestine is exposed to microflora components from birth or hatching, little is known about their impact on healthy development and function. Microorganisms are more densely populated in the GIT than in any other organ [9]. Animals have evolved the ability to host complex and dynamic consortia of microbes over their life cycle during millions of years of evolution [10].

As a result, a detailed understanding of the contributions of these indigenous microbial communities to host development and adult physiology is required for a thorough comprehension of vertebrate biology [11]. Animal species, breed, age, nutrition, environment, rearing forms, stocking density, stress, and medicine can all have an impact on the delicate composition of the gut microbiota [12]. Factors affecting the composition in gut microbiota are shown in Figure 1. Most of these intestinal microflora's species cannot be cultured when they are removed from their niches, as is the case with most complex ecosystems. 
Colonization of avian guts could already start during embryogenesis [13] and progresses to the formation of a complex and dynamic microbial society [14]. Based on principles established during animal history, extensive and combinatorial microbial-microbial and host-microbial interactions are likely to govern the microbiota assembly [15]. Comparing germ-free rodents that were raised without exposure to microorganisms to those that built up a microbiota since birth, or those that were colonized with microbiota components during or after postnatal development, a variety of host functions influenced by indigenous microbial communities were identified [16].

The microbiota, for example, directs the formation of gut-associated lymphoid tissue, aids immune system education, affects the integrity of the intestinal mucosal barrier, modulates proliferation and differentiation of epithelial lineages, regulates angiogenesis, modifies enteric nervous system activity, and plays a critical role in extracting and processing the nutrients consumed $[17,18]$. Proteins and protein breakdown products, sulfur-containing substances, and endogenous or foreign glycoproteins can all be metabolized by the microflora [19]. Some bacteria even feed on bacterial fermentation products or intermediates including $\mathrm{H}_{2}$, lactate, succinate, formate, and ethanol and convert them to end products which are again secreted to the gut lumen, such as short-chain fatty acids (SCFA), a process that has a direct impact on gut physiology [20].

\section{Environmental factors}

Farm management

- Husbandry
- Stocking density
- Temperature
- Photoperiod
- Ventilation
- Feed management
- Feed and water access
- Feed quality
- Litter management
- Litter type
- Litter humidity
- Nutrition
- Feed composition
- Feed ingredients
- Particle size
- Micronutrients
- Enzymes
- Health interventions
- Antibiotic growth promoters
- Vaccination
- Probiotics/Prebiotics
- Plant bioactives

- Husbandry

Stocking density

Temperature

Ventilation

Feed quality

- Litter type

- Litter humidity

Particle size

Micronutrients

Vaccination

- Plant bioactives

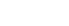

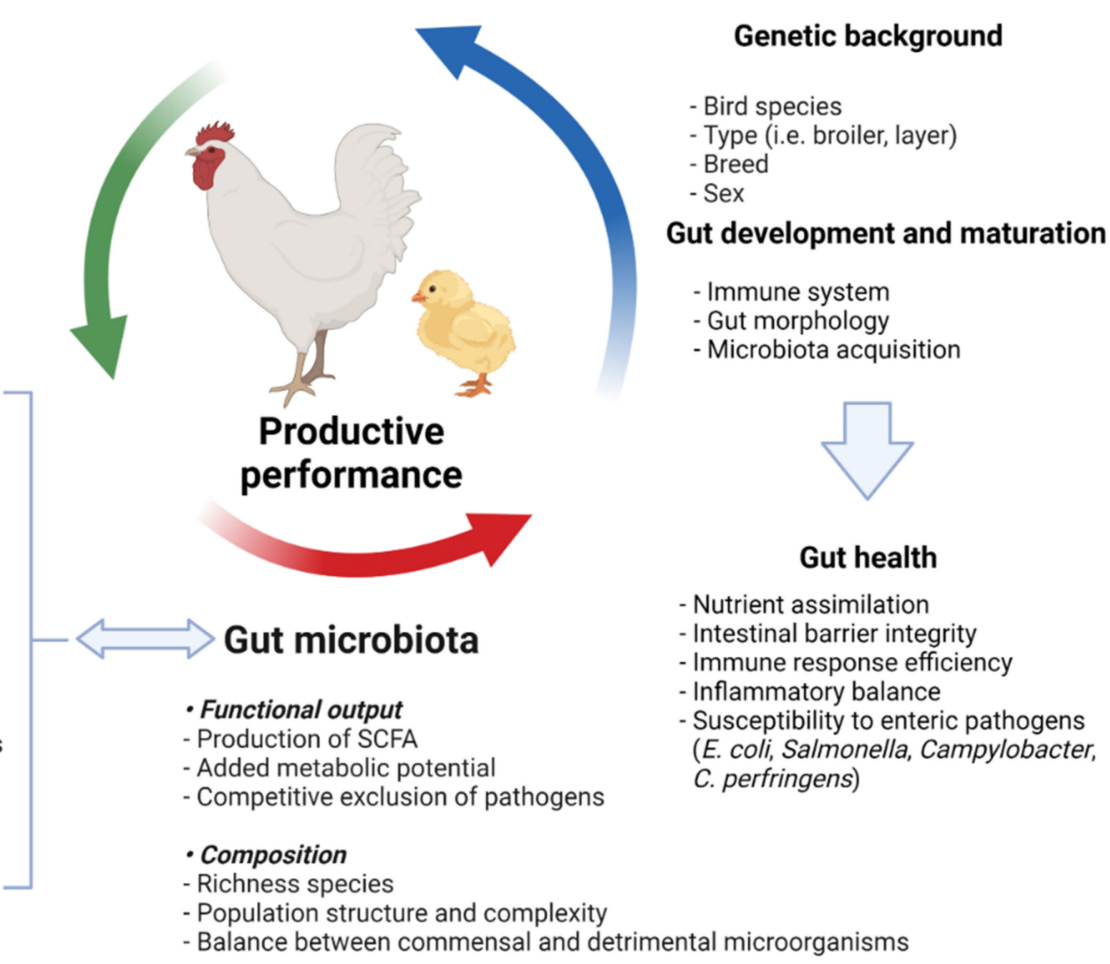

\section{Host factors}

\section{Genetic background}

Bird species

Type (i.e. broiler, layer)

Breed

Gut development and maturation

Immune system

Gut morphology

\section{Gut health}

Immune response efficiency

E. coli, Salmonella, Campylobacter,

Added metabolic potential

Competitive exclusion of pathogen

Balance between commensal and detrimental microorganisms

Figure 1. Factors affecting the gut microbiota composition modified according to Carrasco et al. [21] (figure was created with BioRender.com, accessed on 15 December 2021).

More than $90 \%$ of all gut microbiota species in humans and animals belong to the phyla Bacteroidetes, Firmicutes and Actinobacteria, others are Fusobacteria, Proteobacteria, Verrucomicrobia, and Cyanobacteria [22,23]. In chickens, the phyla Bacteroidetes and Firmicutes are the most predominant representatives in the gut. In human and several animals, the ratio between Firmicutes and Bacteroidetes is a health/metabolism-associated marker [24-27]. Firmicutes species decompose polysaccharides and produce butyrate, and Bacteroidetes species degrade complex carbohydrates and synthesize mainly propionate [25]. The mechanisms by which bacteria exert effects on the gastrointestinal tract are largely unknown, but manipulation of these triggers is considered to be a promising mean to achieve op- 
timal health and performance [28,29]. It is also assumed that the molecular principles that aid in the modification and maintenance of normal physiological functioning of the gut microbiota are mainly derived from food and its supplements, such as nutraceuticals [30]. Nutraceuticals can include everything from isolated nutrients (vitamins, minerals, amino acids, fatty acids) to herbal goods (polyphenols, herbs, spices), dietary supplements (probiotics, prebiotics, synbiotics, organic acids, antioxidants, enzymes), and genetically modified foods. These nutraceuticals also aid in the prevention of infectious diseases of the host [31]. Additionally, several multidrug resistance bacteria have emerged making, this crisis global [32-34]. Nutraceuticals will be required to reduce the use of antibiotics [35].

Lactic acid bacteria have been used as feed supplements since pre-Christian times when humans ingested fermented milk. This subject was not analyzed scientifically until the last century, when Eli Metchnikoff (1845-1916), working at the Pasteur Institute in Paris, discovered a link between human longevity and the importance of maintaining a healthy mix of beneficial and pathogenic microbes in the gut. Elie Metchnikoff received the Nobel Prize in Physiology in 1908 for discovering the role of phagocytes and other components in the immune system, but his correct description of key constituents in the body's gut flora is also noteworthy [36]. He devised and administered bacteriotherapy, or the use of lactic acid bacteria in food regimens, to his patients. He also highlighted the fact that Bulgarian peasants consumed a lot of spoiled milk and lived long lives [36]. From spoiled milk, Metchnikoff and his co-workers identified the 'Bulgarian bacillus,' most likely Lactobacillus bulgaricus, which was employed in later trials.

Today, this microorganism is known as Lactobacillus delbrueckii subsp. bulgaricus, which is one of the bacteria that is used to ferment milk and make yogurt. Following Metchnikoff's death in 1916, the focus of work in this field shifted to the United States. In the late 1940s it was discovered that antibiotics added to farm animals' feed aided their growth [37]. The need to understand the mechanisms behind this impact prompted more research into the composition of the gut microflora and how it can affect the host animal health.

Progress in bacteriology and the easier availability of germ-free animals helped to assess the impact of newly identified intestinal occupants on the host [38]. Based on these studies, it became clear that Lactobacillus acidophilus was not the only Lactobacillus in the intestine, and a variety of other species were examined and eventually included in probiotic formulations. The main representatives in gut microbiota of chickens are summarized in Figure 2. Understanding how the intestine matures and develops in chickens and how feed supplements benefit the gut performance will increase feed efficiency, growth, and overall health [39]. 


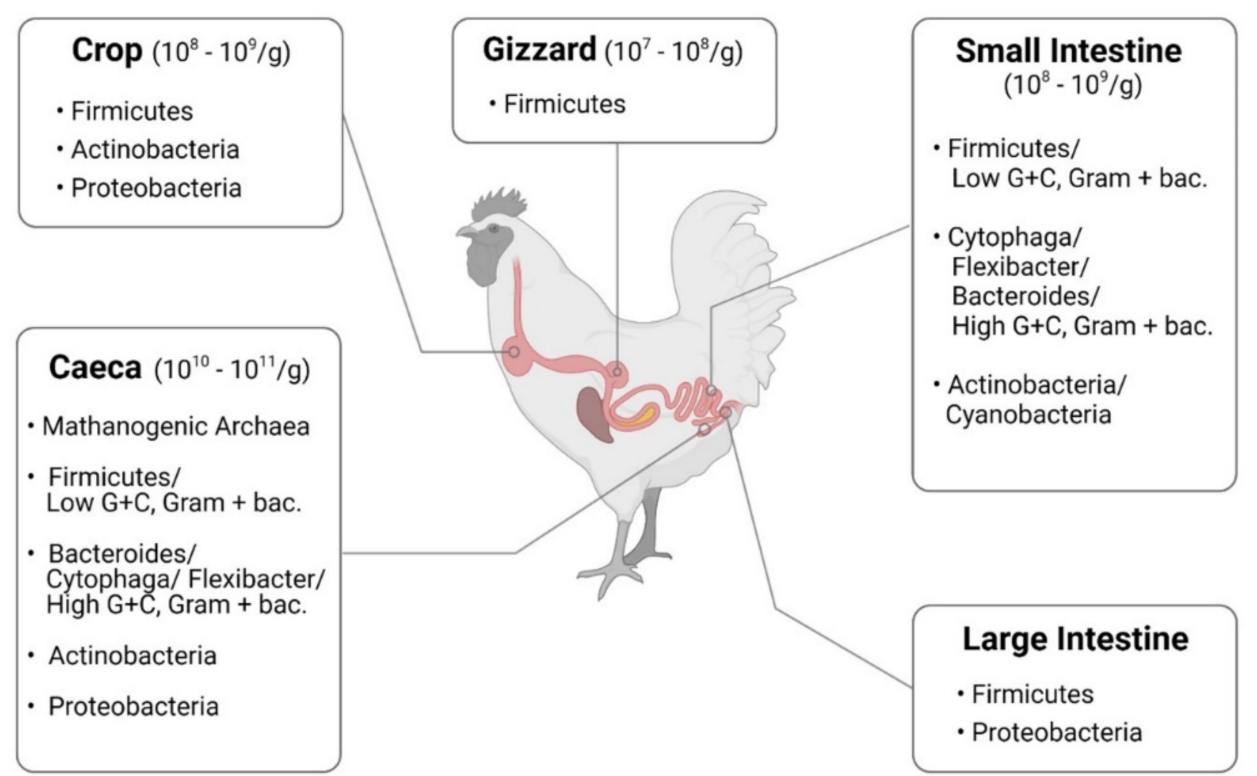

Figure 2. Microbiota in chickens, summarized from Shang et al. [40] (figure was created with BioRender.com, accessed on 15 December 2021).

\section{Intestinal Barrier and Tight Junctions}

Enterocytes are the cornerstone of the intestinal mucosal monolayer that protects the host from the external environment. A scheme of the intestinal epithelial barrier and some interactions with intestinal microbiota is shown in Figure 3. Enterocytes are connected by the so-called tight junctions (TJs), which constitute a continuous belt of intimate contacts formed during the assembly process of integral transmembranes (occludin, claudins, junctional adhesion molecules (JAMs), and tricellulin) and peripheral membranes (zonula occludens-1 (ZO-1), ZO-2, and ZO-3). The TJ proteins are located between adjacent enterocytes, sealing the paracellular space and regulating the permeability of the intestinal barrier. Therefore, these proteins prevent the transit of microorganisms, toxins and other antigens from the intestinal lumen to the systemic circulation [41,42]. The formation and function of tight junctions are controlled by intracellular signal transduction pathways: (i) protein kinase C (PKC), A (PKA), and G (PKG) signaling, (ii) phosphatase-Rho, myosin light chain (MLC) kinase (MLCK), MAPK signaling, and (iii) the PI3K/ Akt pathway [43,44].

The disruption of tight junctions by bacterial factors can occur in the following steps: (i) bacterial lipopolysaccharide (LPS) activates the intestinal epithelial cells and macrophages; (ii) these cells secrete proinflammatory cytokines such as IL-1ß; and (iii) IL-1ß further activates these cells and triggers intracellular signaling, such as p38 MAP kinase, which subsequently activates MLCK. Finally, these processes lead to an increase in intestinal permeability $[45,46]$. Thus, leaky gut syndrome develops as a response to pathogens, feed deprivation, and stress [47-50]. 


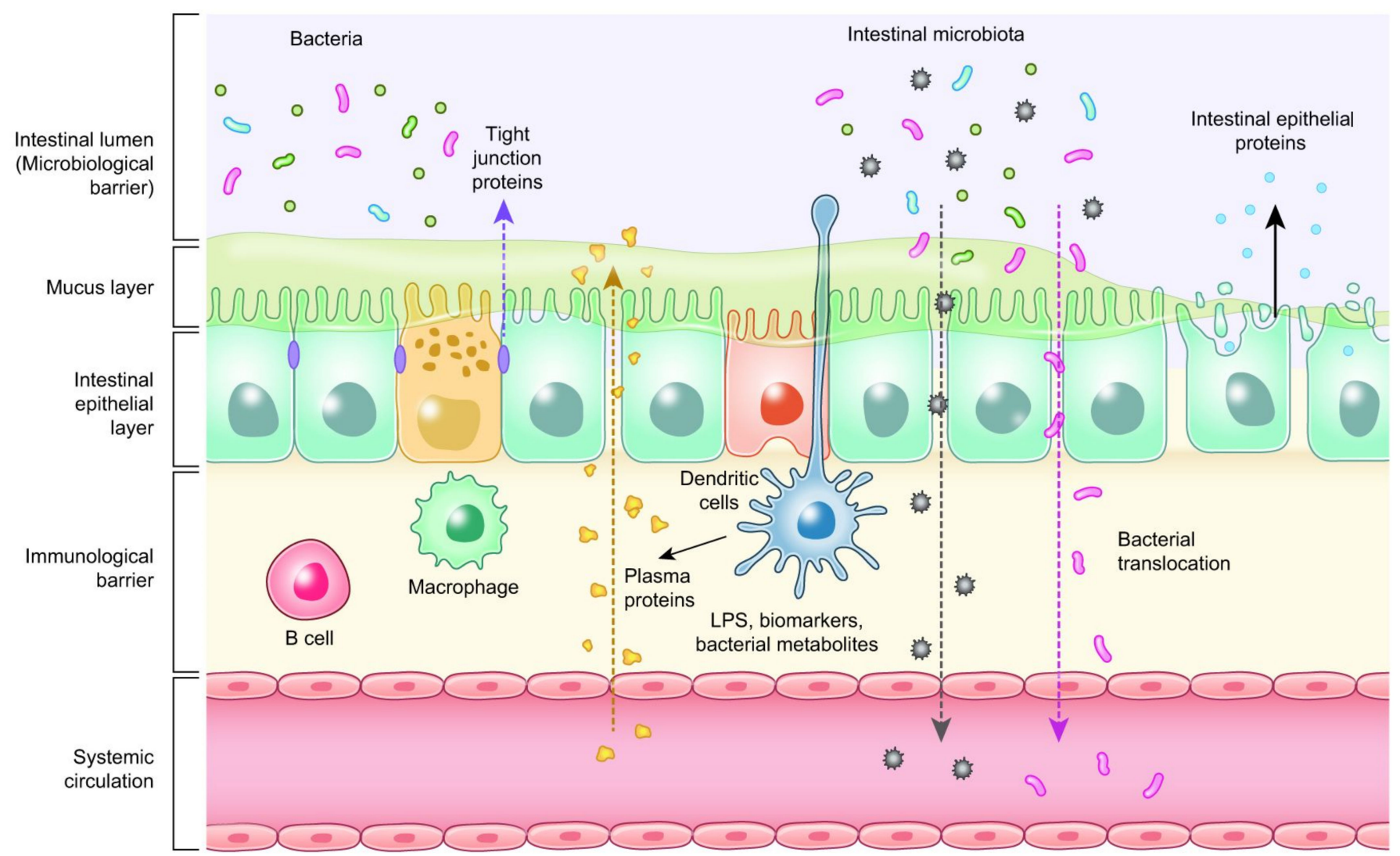

Figure 3. Intestinal epithelial barrier and intestinal microbiota interaction.

\section{Biomarkers Related to Intestinal Health of Animals}

The interactions between the epithelial barrier function, intestinal inflammation, and the microbial environment influence gut health [51,52]. Therefore, the discovery of reliable, widespread biomarkers to measure intestinal inflammation and barrier function is an important ongoing area of research. A summary of some of the known biomarkers related to intestinal health is presented in Table 1. To study intestinal health, it is also important to develop inflammatory gut models with different challenge conditions (anti-nutritional factors, pathogens, toxins, and environmental triggers) [53,54]. Inflammation can also be associated with oxidative stress and changes in the expression of genes related to oxidative stress, indicating that oxidative stress may have a critical role in the physiological intestinal function [55]. One quantitative technique that is used to evaluate the integrity of tight junction proteins in epithelial cell monolayers is the measurement of transepithelial electrical resistance (TEER) [56]. Mitochondrial respiration is required to maintain TEER, implying that oxidation plays a critical role in Caco-2 cell tight junction stability [57]. According to Janssen-Duijghuijsen et al. [57], reduced mitochondrial ATP production resulted in a decrease of intestinal permeability and an increase in occludin and claudin-1 gene expression, but a decrease in claudin- 2 and claudin-7 gene expression. Consequently, a direct connection between mitochondrial function, cellular energy status, and intestinal integrity was established. Often, oxidative stress is quantified by examining metabolites formed during or after an oxidative process. An antioxidant enzyme that detoxifies harmful metabolic byproducts and that is usually measured as a biomarker is superoxide dismutase (SOD) [58]. Other biomarkers that could be used to measure antioxidant activity include thiobarbituric acid reactive substances (TBARS), which are metabolites formed during peroxidation; total antioxidant capacity; and the Griess assay, which utilizes nitrite and nitrate breakdown to determine the concentration of nitric oxide within the cell 
Table 1. Potential biomarkers to evaluate intestinal health.

\begin{tabular}{|c|c|}
\hline Measurement/Function & Biomarker Type \\
\hline Antioxidant activity & $\begin{array}{c}\text { Superoxide dismutase (SOD), Thiobarbituric acid reactive } \\
\text { substances (TBARS), Total antioxidant capacity }\end{array}$ \\
\hline $\begin{array}{l}\text { Gene expression of host protein } \\
\text { biomarkers and tight junction }\end{array}$ & $\begin{array}{l}\text { Fatty acid binding protein (FABP), Fibronectin, Occludin, } \\
\text { Zonula } \\
\text { occludens, Claudins }\end{array}$ \\
\hline Immune activity & $\begin{array}{c}\text { Acute phase proteins, Calprotectin, Lipocalin, } \\
\text { Immunoglobulins (IgA), Interferon gamma (INF- } \gamma \text { ) }\end{array}$ \\
\hline Intestinal permeability & $\begin{array}{c}\text { Fluorescein isothiocyanate dextran (FITC-d), Trans } \\
\text { epithelial electrical resistance (TEER), Bacterial } \\
\text { translocation }\end{array}$ \\
\hline Enterocyte function & Extracellular signal-regulated kinase (ERK), Citrulline \\
\hline
\end{tabular}

Biomarkers for the evaluation of intestinal health can also be related to monitoring intestinal function. Citrulline is a nitrogen-containing by-product of glutamine metabolism that can be converted to arginine and is produced mainly by enterocytes of the small intestine [60]. Plasma citrulline levels have been associated with intestinal absorption of markers such as mannitol in pre-weaned piglets, indicating that citrulline may be utilized to monitor intestinal function [61]. The extracellular signal-regulated kinase (ERK) is another biomarker that can be considered to be an option because it serves as a critical signaling pathway for intestinal epithelial proliferation and tissue healing. Thus, serum ERK activity can reflect intestinal disruption caused by a stressor [62].

In the case of biomarkers related to the immune activity that can influence intestinal health, secretory $\operatorname{IgA}(\mathrm{SIg} A)$ is a critical component of the humoral immune system and the leading immunoglobulin that interacts with pathogens on the mucosa surface. Consequently, it has a close relationship with the homeostasis of the intestinal environment [63]. A proinflammatory cytokine with immunostimulatory and immunomodulatory properties is interferon-gamma (INF- $\gamma$ ). This cytokine has been related to the endocytosis of tight junction proteins. Hence, it has a feasible impact on intestinal permeability $[64,65]$. Ultimately, both innate and adaptive immune responses are likely to provide viable biomarkers for assessing intestinal health.

The histomorphological analysis is another type of evaluation closely influenced by an adequate balance of the intestinal environment. Villus height, crypt depth, and the villus height to crypt depth ratio are parameters that can be used to calculate the area of absorption in the different sections of the intestine, and at the same time be indicative of the epithelial cell turnover in the intestinal barrier [66].

Bacterial translocation and gene expression of TJ such as claudins, occludins, and zonula occludens (ZO-1) are intestinal permeability biomarkers used to evaluate gut health. Bacterial translocation has been related to diseases such as chondronecrosis with osteomyelitis in broiler and broiler breeders $[67,68]$, suggesting the migration of enteric pathogens to the thoracic vertebrae. TJs such as occludin have shown to be downregulated in human patients with inflammatory bowel diseases (Crohn's disease), and in chickens under nutritional gut health challenge condition models $[69,70]$, therefore revealing the fundamental role of TJs such as occludin in maintaining intestinal barrier integrity. Another well-known biomarker that has been utilized in poultry to evaluate intestinal permeability is the measurement of fluorescein isothiocyanate dextran (FITC-d) in the serum. During intestinal inflammation, the disruption of the TJ proteins allows the FITC-d molecule to diffuse into systemic circulation, allowing measurement of this biomarker under different challenging conditions, including $24 \mathrm{~h}$ of fasting in broiler chickens [71].

A different set of biomarkers candidates include the fatty acid binding proteins (FABP), which are intracellular lipid chaperones in charge of orchestrating lipid metabolism and critical lipid-sensitive pathways in macrophages and adipocytes [72]. FABP2 has been studied in humans [73] and in chickens [54], showing a downregulation response when 
there is intestinal barrier injury. Some non-invasive biomarkers that are currently being studied in fecal samples by different research groups are fibronectin, calprotectin, and lipocalin [74]. These biomarker candidates have shown promising results in chickens; nevertheless, there have been also inconsistencies between studies. Ultimately, the objective is to continue searching for intestinal health biomarkers that can be easily measured from samples that do not require an extensive preparation time or cost.

\section{Probiotics}

Properly dosed probiotics improve gut microbial balance, colonization resistance against infections, and immunological responses [75]. Lactobacillus spp., Streptococcus thermophilus, Enterococcus faecalis, and Bifidobacterium spp. are the most frequent lactic acid bacteria (LAB) utilized in probiotic formulations. Possible mechanisms of action include: (i) maintaining a healthy balance of bacteria in the gut by competitive exclusion, i.e., in a process by which beneficial bacteria exclude potential pathogenic bacteria via competition for attachment sites in the intestine and nutrients, and (ii) preventing bacterial overgrowth in the gut [76].

There is also ample evidence that probiotics affect the immune system by balancing pro- and anti-inflammatory cytokines [77]. Some probiotics have antioxidant capabilities and improve barrier integrity [78]. Another study found that both innate and humoral immunity are improved while using probiotics [79]. A commercial lactic acid bacteriabased probiotic (FloraMax PW Boehringer Ingelheim) for poultry use was studied recently. Using this specified LAB culture, extensive laboratory and field research has shown greater resistance to Salmonella sp. infections in hens and turkeys [75-78]. Several probiotic strains improved the animal performance and could be used as potential alternatives to antibiotics [80-86]. Higgins et al., reported that probiotics reduce idiopathic diarrhea in commercial turkey brooding houses, according to published experimental and commercial trials [83]. Additionally, probiotic blend was shown to improve performance and reduce production costs in large-scale commercial experiments [81,84]. Probiotic-treated birds demonstrated variations in gene expression related to the nuclear factor kappa $B$ (NF-kB) complex, according to recent microarray research [85]. These findings indicate that specified probiotic cultures may occasionally be an attractive alternative to traditional antibiotic therapy [86].

Commercial probiotics that are shelf-stable, cost-effective, and feed-stable (resistance to the heat pelletization process) are urgently needed to promote compliance and wider usage. Some probiotic products contain bacterial spore formers, typically of the Bacillus genus. Some (but not all) have been proven to prevent certain gastrointestinal problems. The variety of species employed and their multiple uses are astounding. These means prove the benefit that some Bacillus spore isolates are the most heat-tolerant spores known and can thus also be employed in intense heat circumstances [87]. Thus, spores from selected Bacillus strains have been used as a reliable direct feed microorganisms (DFM) in animal production due to their ability to withstand harsh environmental conditions and long storage periods [88].

Field trials suggested that one strain of Bacillus subtilis spore isolate is as effective as FloraMax PW in reducing Salmonella spp. [89,90]. Further research may reveal further potent isolates or combinations of isolates. Some of these environmental Bacillus isolates have been tested in vitro for antibiotic activity, heat stability, and population growth. Improving amplification and sporulation efficiency is critical to gain industrial approval of a feed-based probiotic for ante-mortem food-borne pathogen intervention. An enhanced vegetative growth and sporulation rate may lead to new efficiencies for commercial amplification and cost-effective product creation at very high spore counts [91].

Bacillus-DFM has also been shown to prevent GIT disorders and provide a variety of nutritional benefits to both animals and humans [92]. In vitro and in vivo studies have shown that $90 \%$ of $B$. subtilis spores germinate in different segments of the GIT within $60 \mathrm{~min}$ in the presence of feed [93]. Moreover, using different poultry diets in vitro (rye, 
wheat, barley, and oat based-diets), the inclusion of selected Bacillus-DFM candidates that produce a different set of extracellular enzymes resulted in a significant reduction in both digesta viscosity and Clostridium perfringens proliferation between control and Bacillus-DFM supplemented diets [70].

The increased digesta viscosity and longer feed passage time caused by high soluble non-starch polysaccharide (NSP) concentrations in poultry diets influence the intestinal bacterial population [94]. Hence, exogenous carbohydrases (xylanase, glucanase, mannanase, galactosidase, and pectinase) are used as feed additives in an attempt to reduce the negative impact of these anti-nutritional factors [94,95]. Interestingly, it was shown that the supplementation of the Bacillus-based DFM improved growth performance, digesta viscosity, bacterial translocation, microbiota composition, and bone mineralization in broiler chickens and turkey fed a rye-based diet $[70,96]$. These differences may be due to fewer substrates available for bacterial growth, resulting in less intestinal inflammation and bacterial translocation when intestinal viscosity was reduced by including the DFM candidate, implying that supplemented groups absorbed more nutrients through the intestinal brush border. The significant improvements in performance observed in turkeys and chickens fed the Bacillus-DFM supplemented diet when compared to the unsupplemented control group suggests that the production of enzymes from the combined Bacillus spp. strains used as DFM can increase nutrient absorption, promoting growth performance and a more efficient feed conversion ratio, in addition to improving intestinal integrity [70,96]. It was shown that this DFM significantly reduces the severity of Salmonella enterica serovar Enteritidis experimental infections [97] and aflatoxicosis [98].

Bacterial translocation, intestinal viscosity, microbiota composition, and bone mineralization in broiler chickens were shown to be affected by rye energy use in one study [44]. However, the Bacillus-DFM reverses the negative effects of high NSP diets in poultry $[63,94]$. Additionally, the performance of broiler chicks and turkey poults was improved by DFM inclusion in reduced fat diets, which was associated with increased energy digestibility as measured by apparent metabolizable energy and nitrogen corrected [99].

\section{Prebiotics}

Prebiotics are a relatively recent concept, arising from the idea that nondigestible food elements (e.g., nondigestible oligosaccharides) are selectively fermented by bacteria known to benefit gut function [75]. The proliferation of endogenous lactic acid bacteria and Bifidobacteria in the gut has been demonstrated to benefit host health [39]. Prebiotics may help Bifidobacteria and lactobacilli to proliferate in the gut, enhancing the host microbial balance. Prebiotics, unlike probiotics, encourage the gut bacteria that have acclimated to the gastrointestinal tract's environment [100]. Other gastrointestinal alterations include increased intestine length in elderly humans [101]. Prebiotics alter the colonic microbiota and may impact gut metabolism in humans [102]. Healthy gut microbiota may increase absorption, protein metabolism, energy metabolism, fiber digestion, and gut maturation in Leptin-Resistant Mice [103]. Prebiotics have also been shown to improve host defense and reduce pathogen-induced mortality in birds [104].

Prebiotics' ability to increase the quantity of LAB in the gut may aid in the competitive exclusion of pathogens from the gastrointestinal tract of birds [39]. The increased intestinal acidity caused by prebiotics may also help to reduce infections in the gut of chickens. Prebiotics have also been shown to boost the immunological response in chickens, resulting in faster infection clearance [105]. For example, prebiotics may directly interact with gut immune cells or indirectly interact with immune cells via preferred colonization of beneficial bacteria and microbial metabolites $[106,107]$. Prebiotics may work similarly to probiotics in supporting chicken intestinal health [73]. Inulin, fructo-oligosaccharides (FOS), mannan-oligosaccharides (MOS), galacto-oligosaccharides (GOS), soya-oligosaccharides (SOS), xylo-oligosaccharides (XOS), pyrodextrins, isomalto-oligosaccharides (IMO), and lactulose are the most commonly utilized prebiotics in poultry [103]. 
Prebiotic research on poultry has been conducted since 1990, resulting in a large library of studies. Prebiotics in broiler feed have been demonstrated to boost lactobacilli levels. Some investigations on the microbial effects of prebiotic supplementation found increased Bifidobacteria and decreased clostridia [108]. Salmonella and coliforms were reduced by some $[109,110]$. The use of prebiotics has also been shown to reduce harmful bacteria such as streptococci and staphylococci in infants [111]. Prebiotics increased intestinal villus height in broiler diets, according to intestinal morphology. Detoxification and elimination processes are enhanced by a healthy population of these helpful bacteria in the digestive tract [112]. Prebiotics have been demonstrated to improve eggshell and bone quality, improve mineral utilization, and improve performance in egg-laying hens [113].

A frequently used prebiotics concerns Aspergillus oryze, which is marketed as Aspergillus meal (AM). AM includes $16 \%$ protein and $44 \%$ fiber and can be used to boost performance in commercial poultry diets with low protein levels [114,115]. The mycelium or A. oryzae also contains beta-glucans, FOS, chitosan, and MOS [116,117]. This substance also benefits chickens by promoting growth, most likely by enhancing feed ingredient absorption and digestibility [116].

Beta-glucan is a potent immunity booster [118]. This unique substance affects the intestinal villi and helps the body fight viral and bacterial invaders [119]. MOS bind toxin active sites and defend the GIT against invasion. FOS and chitosan are non-digestible carbohydrates that are easily fermented by gut flora [120]. It was demonstrated that dietary AM alters intestinal morphometry in turkey poults. It increased the number of acid mucin cells, neutral mucin cells, and sulphomucin cells in the duodenum and ileum, in addition to the villi height and surface area in the duodenum and ileum of neonate poults when compared to the control [121]. Another study found that feeding new-born poults AM prebiotic for 30 days boosted body weight and enhanced feed conversion compared to feeding them a basal control diet [122].

Interestingly, dietary AM prebiotic-fed chicks had lower ileum energy and protein content than control chicks, indicating greater digestion and absorption of those nutrients [123]. Fructooligosaccharides (FOS) have been demonstrated to improve intestinal calcium and magnesium absorption, in addition to bone mineral concentrations [124]. Several studies have shown that probiotics can reduce Salmonella colonization in hens [110,125,126]. Finally, chitosan is a natural biopolymer created by deacetylating chitin, the major component of fungal cell walls and arthropod exoskeletons. As previously stated, chitosan has several benefits, including antimicrobial and antioxidant properties [127]. In agriculture, horticulture, environmental science, industry, microbiology, and medicine, chitosan has also showed promising applications [117]. Moreover, many studies have used chitosan as a mucosal adjuvant, increasing IgA levels [128].

In another study, the efficacy of 0.2 percent dietary AM against horizontal Salmonella spp. transmission was assessed in turkeys and hens [129]. This study found that feeding turkeys and broiler chickens 0.2 percent AM reduced horizontal Salmonella enterica serovar Enteritidis transmission and Salmonella enterica serovar Typhimurium transmission by reducing overall colonization levels. The reduction in Salmonella colonization may be attributed to a synergistic effect of beta-glucan, MOS, chitosan, and FOS found in Aspergillus oryzae mycelium.

Yalçın et al. [130] reported that the yeast cell wall derived from baker's yeast was an effective prebiotic feed additive in broiler feeding due to the increased growth performance, increased humoral immune response, and the reduction in abdominal fat. In another study conducted with laying hens, Yalçın et al. [113] concluded that the yeast cell wall had beneficial effects in the production of low cholesterol eggs and improvement in humoral immunity response.

\section{Synbiotics}

When used in combination with prebiotics, probiotics are termed synbiotics, and have the ability to further improve the viability of the probiotics. Probiotics, prebiotics, and 
synbiotics are now widely used globally. In the following section, we discuss the role of synbiotics on digestive physiology and poultry production.

\subsection{Role of Synbiotics in Poultry Production}

Immediately after hatching, birds must switch from endogenous yolk energy to an exogenous carbohydrate-rich diet [131]. During this vital period, intestine size and morphology change dramatically. Changes in epithelial cell membranes alter the mechanical interface between the host's internal environment and the luminal contents. Studies on early growth nutrition and metabolism in chicks may help optimize nutritional management for optimum growth. The end products digested by symbiotic gut microorganisms can modify not only gut dynamics, but also various physiologic systems [132]. The multiple roles of synbiotics on digestive physiology are summarized in Figure 4.

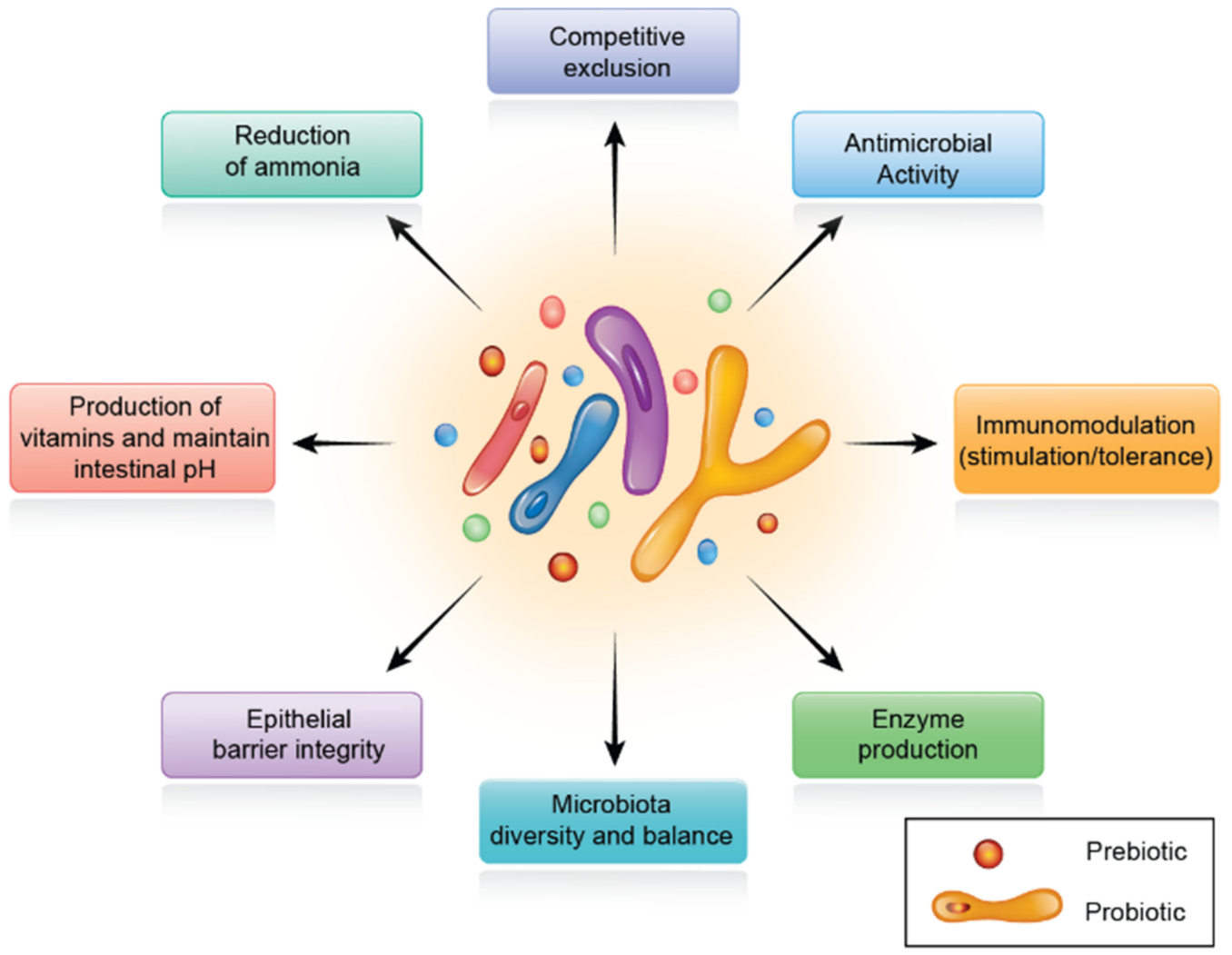

Figure 4. The role of synbiotics on digestive physiology.

\subsection{The Role of Short Chain Fatty Acids (SCFAs) on Digestive Physiology}

The principal fermentative response in humans and chickens is the hydrolysis of nondigestible polysaccharides, oligosaccharides, and disaccharides to simple sugars, which are then further fermented by gut bacteria, for example, into SCFAs. In the large intestine, carbohydrate presence and fermentation can change gut physiology. As the intestinal microbiota are established, the SCFA concentration rises from undetectable levels in the ceca of day-old chicks to the greatest concentration at day 15 [133]. The effects of SCFAs are separated into those in the lumen and those in the big gut wall cells. SCFAs are major luminal anions. Increasing their quantities by fermentation reduces the digesta $\mathrm{pH}$ to a value of approximately 4.8 . SCFAs also provide up to $50 \%$ of the daily energy requirements of colonocytes [134]. Fermentable carbohydrates can drastically alter the microbial ecology by providing SCFAs or substrates. However, SCFAs have multiple roles in host and microbial physiology [135].

Recently, the complex metabolic interaction network of a synthetic gut bacterial community (Oligo-Mouse-Microbiota, $\mathrm{OMM}^{12}$ ) was analyzed in detail by in vitro and in vivo 
methodologies [136]. The study supported the central role of SCFAs in the metabolism of gut bacteria. Hierarchical clustering showed that closely related bacteria in $\mathrm{OMM}^{12}$ produced and consumed similar SCFAs. For example, both Bacteroidales strains in OMM ${ }^{12}$ produced acetic acid, succinic acid, and branched-chain SCFAs, whereas butyric acid, valeric acid, and caproic acid were formed by Clostridium innocuum. This example underscores the diverse metabolic capabilities of gut bacteria and also reflects the delicate metabolic interplay, balanced substrate usages and competition in microbiota.

\subsubsection{SCFAs and Muscular Activity}

In vitro, SCFAs at three millimolar dilates precontracted colonic resistance arterioles in different human colonic segments [79]. Acetate, propionate, or butyrate infusions increased intestinal blood flow [137]. SCFAs affect blood flow without prostaglandins or adrenoreceptors. Local neuronal networks, chemoreceptors, and direct impacts on smooth muscle cells are possible modes of action [20]. Colon SCFAs that enter portal circulation appear to alter upper gut musculature. Not only the colon, but the entire gastrointestinal system, depends on these processes. Greater blood flow should improve tissue oxygenation and nutrition delivery [138].

\subsubsection{SCFAs and Enterocyte Proliferation}

With or without peritoneal delivery, SCFA increases the development of colorectal and ileal mucosal cells in rats. The primary SCFAs (particularly butyrate) appear to reduce the risk of colon cancer [139]. The incorporation of $\left[{ }^{3} \mathrm{H}\right]$ thymidine increased in rats fed deoxycholate plus cholesterol [140]. A low intra-colorectal $\mathrm{pH}$ may be the cause of some SCFA effects. Colonocytes cannot take up protonated and insoluble bile acids at pH 6 . Inhibition of bacterial conversion of primary to secondary bile acids reduces their carcinogenic potential [141]. Similar results have been shown in broiler chickens where combined intra-amniotic and dietary synbiotic treatments improved broiler intestinal integrity and cecal SCFA production, and increased cecal beneficial bacteria populations [142].

\subsubsection{SCFAs and Mucin Production}

Endogenous SCFA synthesis by gut bacteria appears to boost mucus formation and release locally. Moreover, the effects of beneficial or probiotic microbes on mucin synthesis have been studied [137]. The capacity of organisms to limit adherence of attaching and effacing organisms to intestinal epithelial cells appears to be mediated by their ability to promote expression of MUC2 and MUC3 intestinal mucins [143]. Probiotics may have broader application than enteropathogen treatments in poultry. Several studies have demonstrated that probiotics increased mucin synthesis, which decreased rotavirus replication, symptoms, and shedding. The proximal colon's butyrate concentration changed crypt depth and the number of mucus-producing cells. Increased butyrate formation was associated with the number of neutral-mucin-producing cells [125,144].

\section{Phytogenic Feed Additives}

Phytogenic feed additives (PFAs) are classified as sensory and flavoring compounds according to the European Union Legislation (EC 1831/2003) [145]. It has been suggested that PFAs increase the growth performance [146,147], nutrient digestibility [148], and gut health $[146,149,150]$ in poultry. Currently, PFAs are used in feeding programs of poultry and swine. The count of Lactobacillus spp. in the caecum was increased when $75 \mathrm{mg} / \mathrm{kg}$ red ginseng root powder was added as a feed supplement [151]. Several commercial products are based on herbs such as Anise seeds (Pimpinella anisum), Caraway seeds (Carum carvi), Cinnamon bark (Cinnamomum verum), Chamomile flowers (Matricaria recutita), Citrus peel (Citrus sp), Clove buds (Syzygium aromaticum), Fennel seeds (Foeniculum vulgare), Garlic bulbs (Allium sativum), Ginger rhizome (Zingiber officinale), Melissa leaves (Melissa officinalis), Onion bulbs (Allium cepa), Oregano leaves (Origanum vulgare), Peppermint leaves (Mentha 
piperita), Rosemary leaves (Rosmarinus officinalis), Sage leaves (Salvia officinalis), Thyme leaves (Thymus vulgaris), and Valerian root/rhizome (Valeriana officinalis) [152].

These phytogenic substances are promoted due to their safety profiles and qualities to improve the animal performance and health through the following effects: (i) improvement of digestibility, (ii) antimicrobial activities, (iii) anti-inflammatory and antioxidant effects, (iv) stabilization of intestinal microbiota, (v) improvement of animal traits, and (vi) reduction in environmental emissions. In addition to the pharmacological effects, recent studies indicated that phytogenic substances modulate the gut microbiota, namely increase Firmicutes [153,154], Clostridiales, Ruminococcaceae, and Lachnospiraceae [155].

Several factors can modulate the intestinal microbiota causing either a positive or negative effect on the host [156]. Dietary effects on the composition of microbiome are shown in Table 2. Supplementation of day-old chickens with antibiotics negatively modulated the intestinal microbiota and adversely affected the immune system development [157]. It was also found that switching the diet from corn-based to wheat- and barley-based led to an increase in Lactobacillus and coliform [158]. Water-soluble non-starch polysaccharides increased the viscosity of digestive content and the production of SCFAs, which beneficially regulated ileal motility [159].

Table 2. Dietary effect on the composition of the microbiome.

\begin{tabular}{cccc}
\hline Enterotypes & & \multicolumn{1}{c}{ Biological Activities } & Favorable Substance/s \\
\hline Bacteroides & $\bullet$ & $\begin{array}{l}\text { saccharolytic, proteolytic } \\
\text { biotin, riboflavin, pantothenate and } \\
\text { ascorbate synthesis }\end{array}$ & proteins and fats \\
Prevotella & $\bullet$ & $\begin{array}{l}\text { mucin/glycoprotein degrading } \\
\text { thiamine and folate synthesis }[2] .\end{array}$ & high fiber diet \\
& $\bullet$ & mucin/glycoprotein degrading. \\
Ruminococcus & $\bullet$ & transmembrane transport of sugars & Sugars \\
\hline
\end{tabular}

Adapted after [22,160].

In the following section, we discuss the effects of some phytogenic substances that can be used in poultry. Structures of some of these bioactive substances are given in Figure 5. 


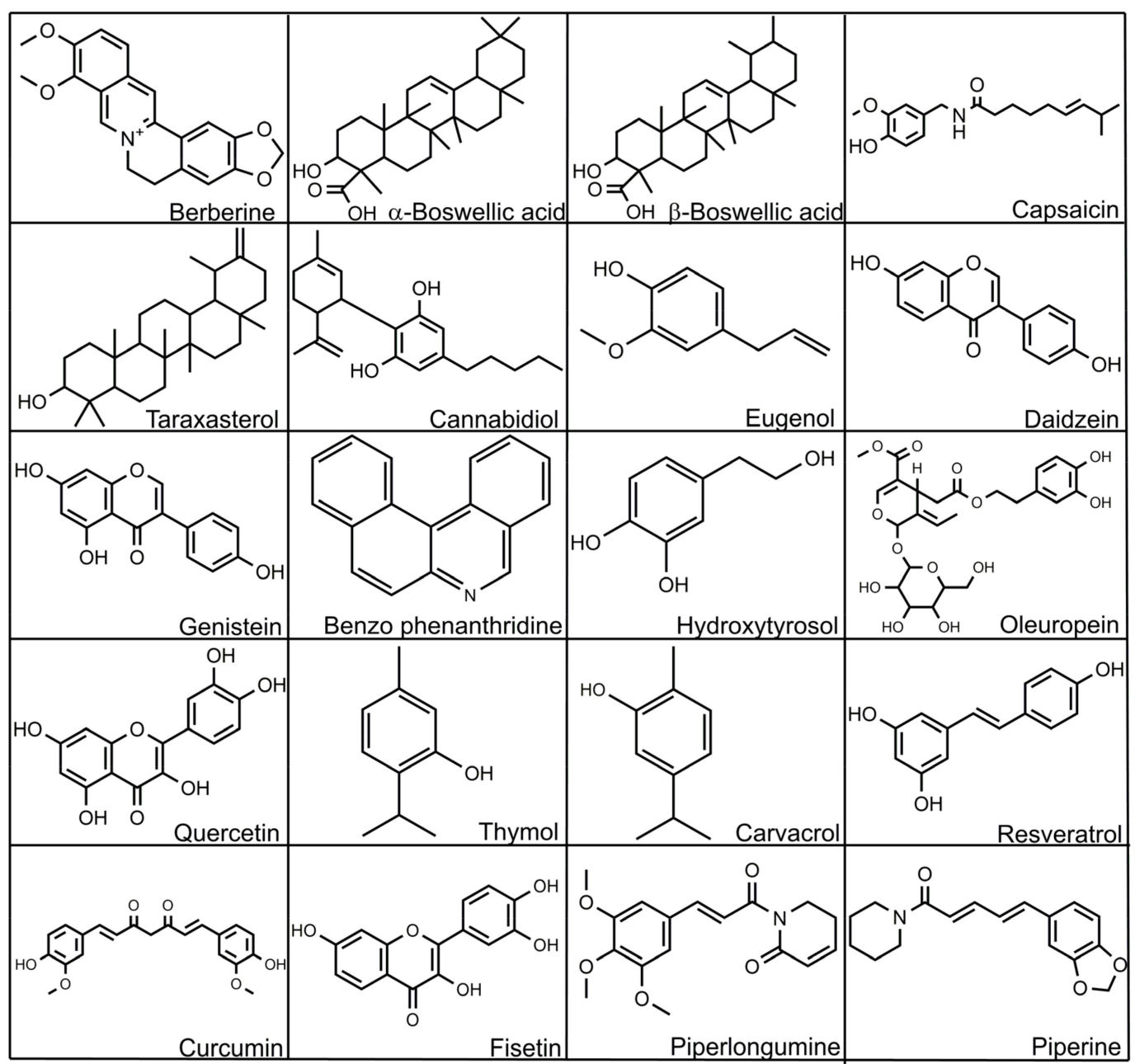

Figure 5. Selected structures of bioactive substances.

\subsection{Berberine}

Berberine is an isoquinoline alkaloid found in several medicinal plants, such as Coptis chinensis Franch, Cortex phellodendri, and Berberis asiatica [161]. Like curcumin, berberine has a poor oral bio-availability (less than 1\%) [162,163]; however, it has a biological effect on gut microbiota. Several pharmacological effects of berberine have been described, including anti-inflammatory [164-167], anti-diabetic [164], anti-atherosclerotic [168,169], and cardio-protective actions [170]. Berberine modulates the pro-inflammatory mediators by reduction in TNF- $\alpha$, IL-1 $\beta$, and IL-6 [171-174]. It was found that berberine significantly reduces IL-17A, IL-17F, IL-6, and IL-1 $\beta$ expression and significantly increases IFN- $\gamma$ and IL-10 in spleens and livers in ducks infected with Riemerella anatipestifer [175].

In a mice model, berberine modulates the gut microbiota by increasing Bacteroides sp., Blautia sp., Akkermansia sp., Lactobacillus sp., and Bifidobacterium sp. [176] and suppression of pathogenic bacteria such as Escherichia coli and Enterococci sp. [176,177]. In poultry, there may be some correlation between berberine's effects on growth performance and modulation of gut microbiota composition and functions. Berberine reduced the abundances of Firmicutes, Lachnospiraceae, Lachnoclostridium, Clostridiales, and Intestinimonas in the gut of broilers, but increased the abundances of the phylum Bacteroidetes and the genus Bacteroides [178]. Berberine can be also used to control coccidial infection and necrotic enteritis in broilers $[179,180]$. Berberine was found to be safe for broiler chickens, even at high doses of $1 \mathrm{~g} / \mathrm{kg}$ in feed [179].

Additionally, the alkaloid was shown to increase the levels of SCFAs, especially under pathological metabolic disorders [176]. In broilers challenged with LPS or E. coli, 
berberine showed antioxidant and anti-inflammatory effects [181,182]. Berberine decreased the mRNA expression of NF- $\mathrm{kB}$, TNF- $\alpha$, IL-1 $\beta$, inducible nitrite synthase, and cyclooxygenase- 2 in the liver [181]. Interestingly, it was suggested that berberine increases the bioavailability of other drugs in broilers by down-regulation of P-glycoprotein (P-gp) efflux [183].

\subsection{Boswellia}

Trees from the genus Boswellia (Burseraceae) are traditionally used as a medicine, a fumigant, in various cosmetic formulations, and in aromatherapy in several countries around the world. Frankincense (olibanum) is the common name given to the aromatic resin produced by a group of trees belonging to the genus Boswellia. Boswellia carteri Birdw., $B$. frereana Birdw. (Somalia) and B. serrata Roxb. (North-western India) are the three main frankincense-producing species [184].

Boswellia serrata oleo-gum resin is a traditional Ayurvedic remedy for inflammatory diseases, and is also known as Salai Guggal, Indian olibanu, or Indian frankincense. It has a woody, spicy, and haunting smell. The phyto-chemical content of B. serrata oleo-gum resin (BSE) is dependent on the botanical origin and consists of 30-60\% triterpenes (such as $\alpha$ - and $\beta$-boswellic acids, lupeolic acid), $5-10 \%$ essential oils, and polysaccharides. The anti-inflammatory properties of $B$. serrata are attributed to the bio-active components, 11-keto- $\beta$-boswellic acid (KBA), and 3-acetyl-11-keto- $\beta$-boswellic acid (AKBA), even if other boswellic acids, such as $\beta$-boswellic acid $(\beta B A)$, may be efficacious.

It has several mechanisms of action, such as inhibition of 5-lipoxygenase (5-LO), decreased cytokine (interleukins and TNF- $\alpha$ ) levels, and reduction in ROS formation [185-187]. $\beta$-Boswellic acid has an anti-inflammatory activity acting through the inhibition of serine protease cathepsin G and microsomal prostaglandin E synthase [188]. Using Caco-2 cell monolayers, Catanzaro et al. tested the impacts of $B$. serrata oleo-gum extract (BSE) and its pure derivative AKBA at $0.1-10 \mu \mathrm{g} / \mathrm{mL}$ and $0.027 \mu \mathrm{g} / \mathrm{mL}$, respectively [189]. BSE and AKBA pretreatment significantly prevented functional and morphological alterations in paracellular permeability and the NF- $\mathrm{KB}$ phosphorylation induced by inflammatory stimuli. At the same concentrations, BSE and AKBA counteracted the increase of ROS caused by $\mathrm{H}_{2} \mathrm{O}_{2}$ exposure. Together, a positive correlation of the antioxidant activity with the mechanisms involved in the physiologic maintenance of the integrity and function of the intestinal epithelium was demonstrated [189]. They also reported that BSE protects the intestinal epithelial barrier from inflammatory damage in human patients suffering from inflammatory bowel disease (IBD) [189]. In rabbits, B. serrata significantly reduced total bacteria counts of E. coli and Salmonella [190].

In broilers, dietary supplementation of Boswellia serrata improved the animal performance by increasing the total antioxidant capacity and the levels of globulin, superoxide dismutase, and digestive enzymes (amylase and lipase), and by reducing the levels of total cholesterol, low-density lipoprotein (LDL), and malondialdehyde (MDA) [191]. It was found that $3 \%$ and $4 \%$ additions of Boswellia in the diet are safe for broiler chickens and improved the body weight, energy digestibility, and carcass quality [192].

\subsection{Capsaicin}

Pepper (Capsicum spp.) is an important vegetable species and a good source of different phytochemicals including vitamin $C$, phenolic compounds, flavonoids, and carotenoids. Therefore, it has significant antioxidant activities $[193,194]$. Chili peppers are increasingly used in food and very popular worldwide. Capsaicin is the main bio-active component in red chili (genus Capsicum) that provides a pungent flavor to food. Capsaicin has been related to several biological effects, including decreased body fat, anti-inflammatory, anticarcinogenic, antioxidant activities, and modulation of intestinal motility.

These actions are mostly due to its role as an agonist of the transient receptor potential vanilloid 1 (TRPV1), expressed in the mesenteric nervous system and epithelial cells of the colon. The anti-inflammatory action of capsaicin is also related to its role in activating 
the peroxisomal proliferator-activated receptor gamma (PPAR $\gamma)$. Experimental studies suggested that capsaicin could reduce intestinal inflammation by a mechanism that could involve not only the TRPV1 receptor but also PPAR $\gamma$ [195]. Kang et al. reported that dietary capsaicin prevented high fat diet-induced metabolic endotoxemia and systemic chronic low-grade inflammation by elevating cecal butyrogenic bacteria and thus the butyrate levels, inhibiting colonic cannabinoid receptor type $1\left(\mathrm{CB}_{1}\right)$ and reducing LPS biosynthesis of bacteria. Therefore, capsaicin prevents gut dysbiosis and metabolic endotoxemia that are linked to chronic inflammatory diseases.

Capsaicin increased the Firmicutes/Bacteroidetes ratio and Faecalibacterium abundance that coincided with the increase in the plasma levels of glucagon-like peptide 1 (GLP-1) and gastric inhibitory polypeptide (GIP), and with the decrease in the plasma ghrelin level in healthy Chinese adults [196]. Poultry do not sense the effect of capsaicin, due to the lack of receptors specific for capsaicin binding $[197,198]$ or the lack of receptors that are sensitive to capsaicin [199]. Nevertheless, in broilers, supplementation of $80 \mathrm{mg} / \mathrm{kg}$ of natural capsaicin extract in diets was found to be safe and improved animal performance by improving nutrient digestibility, antioxidant status, immune function, and meat quality. Capsaicin extract reduced the concentrations of serum TNF- $\alpha$ and IL- $1 \beta$, and increased the total antioxidant capacity of catalase, glutathione peroxidase, and superoxide dismutase [191].

\subsection{Triterpenoids of Marigold}

Calendula officinalis L. (marigold) flower extracts were investigated for their antibacterial, anti-inflammatory [200-203], antitumor-promoting [201], and cicatrizing effects [201], in vitro anti-HIV activity [204], hypoglycemic effects, gastric emptying inhibitory activity, and gastro-protective effects [202]. C. officinalis triterpenoids are considered to be the most important anti-inflammatory principles of the extract [200]. Among these triterpenoids, taraxasterol-3-O-myristate (1) and arnidiol-3-O-myristate (2) were shown to modulate stress damages induced by $\mathrm{H}_{2} \mathrm{O}_{2}$ and INF $\gamma+\mathrm{TNF} \alpha$, underlining the potential use of Calendula extracts against intestinal inflammations [205]. However, in broilers, the supplementation with 5 and $10 \mathrm{~g}$ dried powder of Calendula officinalis $/ \mathrm{kg}$ of diet had no positive influence on growth performance [206]. To the best of our knowledge, marigold effects in poultry microbiota have not been studied. Nonetheless, Rajput et al. reported that dietary supplementation with marigold flower extract increases antibody titers against Newcastle Disease virus (NDV) and Avian Influenza virus (AIV), and growth performance of broilers [207]. Thus, more experiments are needed to investigate the probable effects of marigold in broilers on gut health and microbiota population.

\subsection{Phytocannabinoids}

Phytocannabinoids are terpenophenolic $\mathrm{C}_{21}$ or $\mathrm{C}_{22}$ compounds, which are formed in glandular trichomes of female Cannabis flowers [208]. They have important properties, such as regulating food intake, nausea, emesis, gastric secretion, gastroprotection, gastrointestinal tract motility, ion transport, visceral sensation, intestinal inflammation, and cell proliferation in the gut $[209,210]$. Recently, their potential modulatory activity in GIT has attracted considerable attention. Konieczka et al. [211] reported that cannabidiol (CBD) and nano-selenium improved the gut barrier functions in chickens through increased expression of genes controlling gut integrity. Moreover, $\mathrm{CBD}$ and nano-selenium may be able to modulate the response of chickens to $C$. perfringens infection, which may allow time for effective intervention [208]. Using the Caco-2 cell culture model of intestinal permeability, it was concluded that the cannabinoids may play a role in modulating intestinal permeability by increasing the TJ protein zona occludens-1 [212].

\subsection{Eugenol}

Eugenol is a volatile phenolic constituent of clove essential oil obtained from $\mathrm{Eu}$ genia caryophyllata buds and leaves, mainly harvested in Indonesia, India, and Madagascar. 1,2-Eugenol is the main constituent (70-90\%) of clove oil and is responsible for 
the clove aroma [213]. Clove oil has antimicrobial, antifungal, antiviral, antioxidant, antiinflammatory, and anticancer properties [214]. Authors found that clove essential oil significantly modulated global gene expression and altered signaling pathways critical for inflammation, tissue remodeling, and cancer signaling processes. The results of this study also suggest clove essential oil is an anti-inflammatory, immune-modulating, and tissue remodeling agent in poultry. A recent study reported positive effects of a microencapsulated product composed of eugenol on performance under a subclinical necrotic enteritis [215]. However, the mode of action of plant extracts in mitigating necrotic enteritis effects on intestinal health is not well documented. In another recent study, it was also noted that birds fed eugenol and garlic had reduced CLDN5 expression in male birds, and Bacteroides spp. in female birds, than in the control group [216], suggesting that eugenol and garlic supplementation mitigates the effect of necrotic enteritis by improving the intestinal health of birds.

\subsection{Isoflavones (ISF)}

During the last decade, scientists have paid more attention to isoflavones (ISFs), for example, daidzein, genistein, and glycitein, due to their noticeable benefits to human health [217]. Indeed, several studies showed that ISFs have antioxidant properties [218], can enhance the immune system [219], prevent breast cancer, lower the risk of osteoporosis, decrease the plasma cholesterol level, and boost the anti-oxidative potential in humans and animals [220]. Bacteria that colonize the digestive tract are known to modify ISFs, which are represented in plants as both glycosides and aglycones. Before ISFs can be absorbed from the gut, the sugars of the glycosides must be deconjugated by $\beta$-glucosidases expressed by intestinal bacteria and, subsequently, ISFs enter the bloodstream via passive absorption [221]. Mammalian $\beta$-glucosidase activity does not appear to substantially contribute to deconjugation of ISF glycosides in monogastric animals due to its lower expression level [222]. Supplemental $10-20 \mathrm{mg} / \mathrm{kg}$ ISF may have a positive effect on broiler chickens infected with infectious bursal disease virus, probably because ISFs decrease the severity of bursa lesions and viral protein $5 \mathrm{mRNA}$ expression, a protein produced in response to IBDV to drive apoptosis, and have strong antioxidant activity [223]. One study highlighted the positive benefits of an ISF-rich diet on broiler chickens suffering from the infectious bursal disease virus. Dietary ISF improved the overall health and condition of infected chickens. Further antioxidative properties of ISFs in male broilers are described by the consumption of 40 or $80 \mathrm{mg}$ ISF per kg bodyweight, which leads to an increased antioxidant capability and superoxide dismutase activity in plasma [218].

As a dietary supplement, ISF has recently gained popularity, especially for late-laying stages of egg production that require hormonal replacement to increase production. It has been suggested that the level of endogenous estrogen, individual variation, duration, and dose of phytoestrogen are factors affecting its effects on estrogen [224]. According to several studies, ISF improved animal growth and reproduction [218,225-227]. Furthermore, Shi et al. [227] reported that feeding ISF to laying hens at 59 weeks of age resulted in an increase in egg production. Additionally, dietary daidzein at 10,20 , and $30 \mathrm{mg} / \mathrm{kg}$ increased egg weight and fertility [228]. Moreover, a diet containing daidzein significantly improved the productivity of Shaoxing duck breeders during late laying [229]. Improvements in eggshell quality and laying performance were also observed in the post-peak laying stage of hens [230]. Furthermore, feeding quails during the late laying stage significantly improved egg quality and bone mineralization [231].

Calcium ions are essential components in bone and eggshell formation. Studies have shown that ISF decreases $\mathrm{Ca}^{2+}$ concentration in osteoclasts [232], and as a result, more $\mathrm{Ca}^{2+}$ is available for the eggshell formation process. Studies conducted by Zhao et al. [229] and Sahin et al. [226] confirmed that chicken and quail eggshells develop better when the diet was supplemented with the ISF daidzein. 


\subsection{Isoquinoline Alkaloids}

Herbal extracts from Macleaya cordata (plume poppy) are rich in isoquinoline alkaloids (IQAs), particularly in benzo phenanthridine and protopine alkaloids such as sanguinarine [233]. Le et al. [234] reported that IQAs prevented in heat-stressed pigs the increases in macromolecule permeability of the intestine, and therefore protected mucosal integrity. Beneficial effects of sanguinarine on reducing colonic leakiness have also been demonstrated in a model of colitis in rats [235]. Robbins et al. [236] found that integrity was improved in pigs fed a diet containing $1.5 \mathrm{mg}$ of benzo[c]phenanthridine alkaloids per $\mathrm{kg}$ of feed. The potential mechanisms of action of QBAs are not currently known, but may include modulation of gastrointestinal microbiota, enhancement of intestinal protection, and repair of the intestinal epithelium. Liu et al. [237] reported that the introduction of $M$. cordata extract supplements to the pig's diet increased volumes of ZO-1 and claudin- 1 . The findings of this study indicated that $M$. cordata extract enhances intestinal barrier function in growing piglets and that it can be used as a viable substitute for antibiotics. To the best of our knowledge, the IQA effects in poultry have not been studied. Nonetheless, IQA supplementation may be used as a nutritional strategy to improve gut health and prevent the occurrence of a leaky gut, thereby maximizing the usage of nutrients for performance of pigs, but probably also of poultry.

\subsection{Phenolic Derivatives}

Olive tree (Olea europaea L.) is one of the most relevant botanical drugs in traditional Mediterranean medicine, and olive leaf extracts have been used with different purposes including anti-hypertensive, anti-atherogenic, anti-inflammatory, hypoglycemic and hypocholesterolemia activities [238]. These extracts contain many potentially bio-active compounds, especially phenolic derivatives, such as phenolic acids, phenolic alcohols (hydroxytyrosol), flavonoids, and secoiridoids (oleuropein) [239]. Olive oil phenolic compounds contribute to maintaining gut barrier integrity by upregulating the expression of genes involved in maintaining tight junctions between intestinal cells, modulating the oxidative status of the intestinal epithelial layer, in addition to the inflammatory and immune response [240-242]. In addition, phenolic compounds extracted from olive leaves may be beneficial to broilers through their antimicrobial activity against intestinal pathogenic bacteria [243]. Firmicutes was the predominant phylum in the caeca of broiler fed diets contained $750 \mathrm{ppm}$ of an olive pomace [244]. Liu et al. showed that administration of hydroxytyrosol to high fat diet-induced obese mice increased gene expression for the tight junction-associated proteins ZO-1 and occludin [245], and reduced levels of plasma lipopolysaccharides and inflammatory cytokines in the liver [245]. Thereby, it was concluded that hydroxytyrosol has an important role in promoting intestinal barrier integrity. Vezza et al. [246] reported that olive leaf extract supplementation improved the epithelial barrier function in the models of experimental colitis as demonstrated by the increased expression of the mucin MUC-2, the tight junction protein ZO-1, and TFF-3 [246]. They concluded that intestinal anti-inflammatory activity of olive leaf extract in colitis mouse models may be related to its immunomodulatory properties and the capacity to restore the intestinal epithelial barrier.

\subsection{Quercetin}

Quercetin is the most common flavonoid in nature and can be found in fruits and vegetables including onions, kale, and apples. Quercetin in onion peel has higher bioavailability than that of apple peel [247]. It is one of the most investigated polyphenols exhibiting various health-promoting properties, for example, antimicrobial, antioxidative, anti-inflammatory, and metabolic effects [248]. Quercetin induces their antibacterial activity by acting as DNA gyrase on various cell targets, bacterial membrane and motility, type II fatty acid biosynthesis pathway, and D-alanine:D-alanine ligase enzyme inhibitor $[249,250]$. Abdel-Latif et al. observed that the total coliforms and C. perfringens were decreased $(p<0.05)$ in quercetin-supplemented groups $(200-800 \mathrm{ppm})$. Conversely, Lactobacillus 
counts were increased $(p<0.05)$, due to improvement in the gut microbiota environment in quercetin-supplemented groups [251]. Quercetin is a flavonoid that has been proposed to exert beneficial effects over the intestinal barrier function in human intestinal Caco-2 cell monolayers. Suzuki and Hara [252] reported that quercetin enhances the intestinal barrier function through the assembly of zonula occludens ( $\mathrm{ZO}$ )-2, occludin, and claudin-1 by inhibiting protein kinase $\mathrm{C} \delta(\mathrm{PKC} \delta)$. The increase in claudin-4 expression has an additional role after $12 \mathrm{~h}$. Amasheh et al. [253] evaluated the effects of quercetin on cytokine-induced intestinal barrier damage, both in HT-29 cells and in the distal colon from male Wistar rats ex vivo. Quercetin exerts a protective effect on the intestinal barrier by down-regulating claudin-2. The analysis of intestinal permeability in rat colon ex vivo revealed that quercetin partially inhibited the effects of TNF- $\alpha$ and IFN- $\gamma$ that reduced the total resistance of the intestinal barrier [253]. Carrasco-Pozo et al. [254] evaluated the protective effect of quercetin on ZO-1 and occludin in Caco-2 cells treated with indomethacin and rotenone (an environmental toxin). Treatment with quercetin protected $\mathrm{ZO}-1$ delocalization and prevented the decrease in ZO-1 and occludin expression. The authors hypothesized that quercetin's effects may be due to its mitochondrial-protecting property. However, it may also be the result of a modulatory effect of quercetin on the activity of various intracellular signaling molecules that regulate the integrity of TJ. Quercetin inhibited isoform-mixed protein kinase C (PKC) [255] and phosphoinositide-3-kinase (P13K) [256].

\subsection{Thymol/Carvacrol}

Oregano and thyme are members of the Lamiaceae family, an aromatic herb used extensively in food to add a distinctive aroma and flavor. Their active principles are reported to have antihelminthic, antiseptic, expectorant, antispasmodic, antifungal, antimicrobial, immunostimulating, hypocholesterolemia, antioxidative, antiviral, carminative, sedative, and diaphoretic effects [257-259]. Thymus vulgaris L. contains 1-2.5\% essential oil containing monoterpenes, mainly thymol and its phenol isomer carvacrol. Phenolics in essential oil, such as caffeic acid and p-cymene-2,3-diol, and some biphenylic and flavonoid compounds, such as flavonoid glycosides and flavonoid aglycones, are assumed to contribute various beneficial effects in animals [257,258,260]. Modulation of gut microbiota by carvacrol and thymol and their biological effects are shown in Figure 6.

In the study of Turner [261], thyme oil supplementation to rabbit diets increased TEER values of the intestinal wall. This result showed that thyme oil supplementation has a positive effect on the intestinal barrier. Placha et al. [262] also reported that thyme oil may strengthen the intestinal barrier. Dietary supplementation with $0.5 \mathrm{~g} / \mathrm{kg}$ dry matter thyme oil may improve intestinal integrity. Yalçın et al. [260] showed antioxidative and hypolipidemic effects of thyme supplementation in laying hens along with improved humoral immune response without negative effects on performance and egg quality characteristics. Yoshino et al. [263] reported that oregano extract exhibited iron-reducing activity, although its strength was approximately one-fifth of that of ascorbic acid. Oregano extract administration prevented mouse gastritis induced by cold-restraint stress. The antioxidant activities of oregano extract appear to contribute to its preventive effects against inflammatory diseases such as stress-induced gastritis in mice. Han and Parker [264] reported that oregano essential oil inhibited the levels of many inflammatory and tissue remodeling biomarkers, including MCP-1, VCAM-1, ICAM-1, IP-10, ITAC, IP-10, MIG, collagen I, collagen III, M-CSF, EGRF, MMP-1, PAI-1, TIMP1, and TIMP2. With the analysis of genome-wide gene expression, it was also shown that oregano essential oil exerted a robust and diverse impact on many genes and signaling pathways, many of which are critically involved in inflammation, tissue remodeling, and cancer signaling processes. Oregano essential oil, having carvacrol as the major active component, is a promising candidate for use in skin care products with anti-inflammatory and anticancer properties [264]. Avola et al. reported that oregano essential oil has a property of treating inflammation and supporting cell motility during wound healing in a human keratinocytes cell model [265]. Both thymol or carvacrol up-regulated the mRNA expression of occludin, $\mathrm{ZO}-1$, and claudin- 1 in the small intestine 
<smiles>Cc1ccc(C(C)C)cc1O</smiles>

of broiler chickens [266,267], strengthening the tight junctions. Additionally, thymol and carvacrol improved the digestive enzyme activities through increasing the activities of amylase, protease, and lipase [268]. The increased digestive enzyme activities may be attributed to their antibacterial activity and modulatory effects on gut microbiota [269], resulting in less pathogen-induced damage of enterocytes.
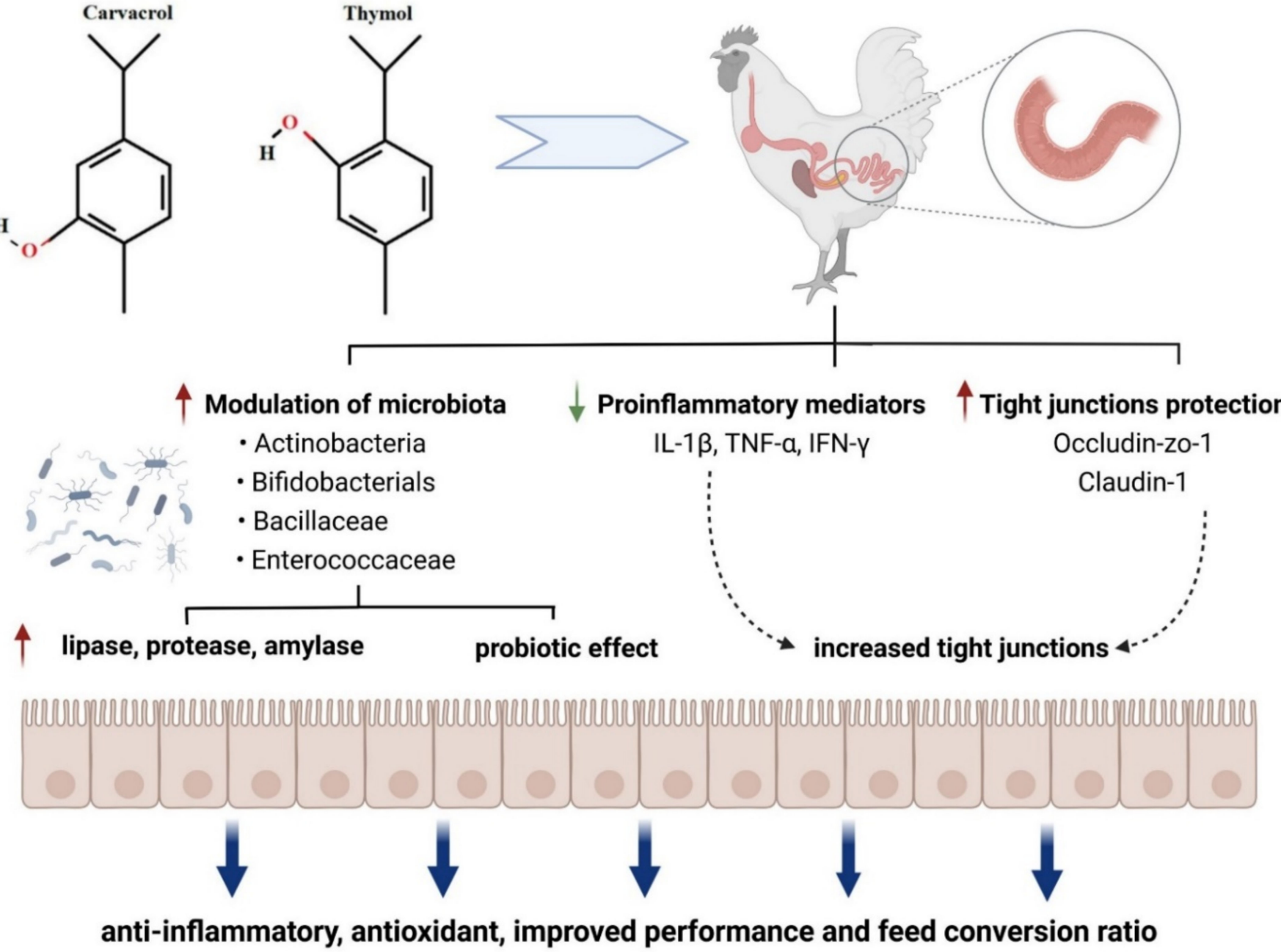

Figure 6. Modulation of gut microbiota by carvacrol and thymol and their biological effects, modified from Feng et al. [270] (figure was created with BioRender.com, accessed on 15 December 2021).

\subsection{Resveratrol}

Resveratrol is a naturally occurring polyphenolic compound found in various plants, including grapes, Polygonum cuspidatum, and peanuts [271]. It has several biological effects, including anti-inflammation [272,273], anti-oxidation [272,274], and energy metabolism regulation [275]. Mayangsari and Suzuki [276], and Blaster [16], found that resveratrol can protect the integrity of human Caco-2 colonic epithelial cells' tight junctions and improve intestinal epithelial barrier function. Zhao et al. [277] reported that resveratrol can maintain the intestinal barrier's integrity and reduce intestinal damage by inhibiting the apoptosis of intestinal epithelial cells of rats. In broilers reared under normal ambient temperature, resveratrol can improve the muscle antioxidant function [278]. Moreover, resveratrol exerted beneficial effects on intestinal morphology [271], the spleen, and muscle antioxidant capacity [271] of broilers under heat stress. The mechanism by which resveratrol enhances the intestinal antioxidant capacity is mediated by the Nrf2 signaling pathway [279]. Resveratrol modulated the gut microbiota by increasing the Lactobacillus sp., Bifidobacterium sp. Bacteroidetes, Akkermansia sp. and Ruminococcus sp., whereas the levels of Lactococcus 
sp., Clostridium spp., Oscillibacter spp., Hydrogenoanaerobacterium sp. were reduced [280]. It improves the tight junction and reduces the permeability of LPS [281,282].

\subsection{Curcumin}

Curcumin is a major active component of the food flavor turmeric, isolated from the powdered dry rhizome of Curcuma longa Linn. Curcumin is characterized by the following: (i) based on FDA, WHO, and EFSA, oral administration is safe and the ADI is $0-3 \mathrm{mg} / \mathrm{kg}$ [283]; (ii) it is highly resistant to low $\mathrm{pH}$, not metabolized in the stomach [284]; (iii) it is absorbed from the large intestine and detected in blood as glucuronide conjugates and sulfate conjugates; (iv) it is metabolized in enterocytes and hepatocytes by reductase to di-, tetra-, and hexa-hydrocurcumin [285-287]; and (v) it shows poor gastrointestinal absorption and low bioavailability, mainly attributed to water insolubility, and rapid metabolism and excretion [288]. In rats, about $75 \%$ of curcumin was excreted in the feces, and a very low amount was detected in the urine [289]. Natural products such as piperine, in addition to nano-formulations, increased curcumin bioavailability [290,291].

Curcumin is said to have a variety of pharmacological activities, including antioxidative, anti-inflammatory, anti-carcinogenic, antidiabetic, and anti-HIV effects [292]. It was shown that curcumin induces several endogenous antioxidants in cultured intestinal disorders and reduces mucosal injury in trinitrobenzene sulfonic acid-induced colitis in vivo [293,294]. Some studies [295-297] reported that curcumin has cytoprotective properties by inducing the protective protein Heme oxygenase-1 (HO-1). Curcumin prevented TNF- $\alpha$-induced decrease in zonula and occluden-1 (ZO-1) protein levels in Caco-2 cell layers [294].

It was proposed that curcumin exerts its main regulative effects primarily in the gut, especially following oral administration of high doses [237]. Interestingly, the interaction between curcumin and gut microbiota is bidirectional. On the one hand, gut microbiota enzymes play a role in the metabolism of curcumin through reduction, acetylation, hydroxylation, demethylation, and demethoxylation [298]. On the other hand, curcumin modulates the gut microbiota, improves intestinal barriers models [46,293,294,299], and counteracts pro-inflammatory mediators [300]. Curcumin reduced Ruminococcus species that are linked with colorectal cancer (CAC) in the mice model, and increased the relative abundance of Lactobacillales and decreased the fraction of Coriobacterales [301,302].

Curcumin can thus be helpful for treatment of intestinal disorders through the following effects: (i) It protects intestinal epithelial cells against $\mathrm{H}_{2} \mathrm{O}_{2}$-induced disruption of tight junction (TJ) and barrier dysfunction via the HO-1 pathway. (ii) It restores occludin enzyme and ZO-1 protein levels after $\mathrm{H}_{2} \mathrm{O}_{2}$ treatment. Its effects were tested on Caco-2 cells and HT-29 cells, and it was found that curcumin can reduce the disruption of intestinal epithelial barrier functions [303]. (iii) Curcumin can also reduce the release of IL-1b secreted by LPS, induce IEC and macrophages, and prevent the disintegration of tight junction proteins, such as ZO-1, claudin-1, claudin-7, and actin filaments [46]. Therefore, it was concluded that curcumin is a potential compound for treating intestinal barrier injury through increasing the expression of tight junction proteins. In specific pathogen-free (SPF) chickens experimentally infected with Eimeria maxima, curcumin reduced the enteric isoprostane 8-iso-PGF2 $\alpha$ and prostaglandin GF2 $\alpha$. Additionally, it proved to be effective to reduce Salmonella enterica serovar Typhimurium intestinal colonization and maintain better intestinal homeostasis in chickens [304]. To improve the bioavailability of curcumin, nanocapsules may be a future strategy.

\section{Conclusions}

It is critical in modern animal production systems to shift the status from survival to creation; that is, minimize the impacts of chronic inflammation and excessive stress so that chickens can utilize their energy for growth rather than defense. Although there is no "magic bullet" for preventing the multifactorial conditions associated with chronic stress, numerous studies have shown that alternative products, such as probiotics, direct- 
fed microbials, prebiotics, and phytochemicals, can help to improve intestinal microbial balance, metabolism, and gut integrity. These feed additives have been demonstrated to have anti-inflammatory, antioxidant, immunological modulatory, and barrier integrityenhancing characteristics. As far as we are aware, no harmful effects have been reported with the use of the nutraceuticals in poultry discussed in the present review. To meet their health and productivity goals, poultry farmers who have eliminated antibiotics from their production systems may utilize a combination of alternative products in conjunction with enhanced management methods, rigorous biosecurity, and effective immunization programs. The relevance of dietary items and their quality, in addition to the absence of Mycoplasma spp. and Salmonella spp. from genetic lines, cannot be overstated. Any kind of stress induces intestinal inflammation, oxidative stress, and lipid peroxidation of vital cellular components, such as the cell and mitochondrial membranes. Damage to these organelles compromises cell homeostasis and the birds' health and productivity. All animals have efficient mechanisms to avoid oxidative stress, such as glutathione peroxidase or superoxide dismutase. Nevertheless, chronic stress and chronic inflammation can overload the bird's system. Antibiotic-free poultry production systems employ alternative natural products, such as those discussed in this review, to reduce the effects of inflammation, colonization risk, and transmission of food-borne pathogens. These products also serve as strategies to maintain human and animal health and food safety in poultry production systems.

Author Contributions: Conceptualization, A.A.S., S.B. and G.T.-I.; methodology, A.A.S. and G.T.-I.; software, A.A.S., A.A.E.-W., J.D.L., S.B. and G.T.-I.; validation, A.A.S., A.A.E.-W., S.B. and G.T.-I.; formal analysis, A.A.S., S.Y., J.D.L., S.B., Y.A.A., A.A.E.-W., C.V., H.R.E.-S., C.H., H.M.H., W.E. and G.T.-I., investigation; writing - original draft preparation A.A.S., S.Y., J.D.L., S.B., Y.A.A., A.A.E.-W., C.V., H.R.E.-S., C.H., H.M.H., W.E. and G.T.-I.; writing-review and editing, A.A.S., S.Y., J.D.L., S.B., Y.A.A., A.A.E.-W., C.V., H.R.E.-S., C.H., H.M.H., W.E. and G.T.-I.; visualization, A.A.S., G.T.-I, H.M.H., W.E. and C.V.; supervision, A.A.S., G.T.-I., H.M.H., W.E. and C.V.; project administration, A.A.S., G.T, H.M.H., W.E. and C.V.; funding acquisition, G.T.-I. All authors have read and agreed to the published version of the manuscript.

Funding: C.H. and W.E. thank the BMBF "Maßgeschneiderte Inhaltsstoffe 2" (ASPIRANT, grant number 031B0823D) and the Hans-Fischer-Gesellschaft (Munich, Germany) for financial support.

Institutional Review Board Statement: Not applicable.

Informed Consent Statement: Not applicable.

Data Availability Statement: Not applicable.

Acknowledgments: Figures 1, 2 and 5 were created with BioRender.com, accessed on 15 December 2021.

Conflicts of Interest: The authors declare no conflict of interest.

\section{References}

1. BisBischoff, S.C.; Barbara, G.; Buurman, W.; Ockhuizen, T.; Schulzke, J.-D.; Serino, M.; Tilg, H.; Watson, A.; Wells, J.M. Intestinal Permeability-A New Target for Disease Prevention and Therapy. BMC Gastroenterol. 2014, 14, 189. [CrossRef]

2. Zoetendal, E.G.; Rajilic-Stojanovic, M.; de Vos, W.M. High-Throughput Diversity and Functionality Analysis of the Gastrointestinal Tract Microbiota. Gut 2008, 57, 1605-1615. [CrossRef]

3. Ackermann, W.; Coenen, M.; Schrödl, W.; Shehata, A.A.; Krüger, M. The Influence of Glyphosate on the Microbiota and Production of Botulinum Neurotoxin During Ruminal Fermentation. Curr. Microbiol. 2015, 70, 374-382. [CrossRef]

4. Schrödl, W.; Krüger, S.; Konstantinova-Müller, T.; Shehata, A.A.; Rulff, R.; Krüger, M. Possible Effects of Glyphosate on Mucorales Abundance in the Rumen of Dairy Cows in Germany. Curr. Microbiol. 2014, 69, 817-823. [CrossRef] [PubMed]

5. Krüger, M.; Neuhaus, J.; Herrenthey, A.G.; Gökce, M.M.; Schrödl, W.; Shehata, A.A. Chronic Botulism in a Saxony Dairy Farm: Sources, Predisposing Factors, Development of the Disease and Treatment Possibilities. Anaerobe 2014, 28, 220-225. [CrossRef]

6. Abuajamieh, M.; Kvidera, S.K.; Fernandez, M.V.S.; Nayeri, A.; Upah, N.C.; Nolan, E.A.; Lei, S.M.; DeFrain, J.M.; Green, H.B.; Schoenberg, K.M.; et al. Inflammatory Biomarkers Are Associated with Ketosis in Periparturient Holstein Cows. Res. Vet. Sci. 2016, 109, 81-85. [CrossRef]

7. Hafez, H.M.; Shehata, A.A. Turkey Production and Health: Current Challenges. Ger. J. Vet. Res. 2021, 1, 3-14. [CrossRef] 
8. Gernat, A.A.; Santos, F.B.O.; Grimes, J.L. Alternative Approaches to Antimicrobial Use in the Turkey Industry: Challenges and Perspectives. Ger. J. Vet. Res. 2021, 1, 37-47. [CrossRef]

9. López-García, P.; Eme, L.; Moreira, D. Symbiosis in Eukaryotic Evolution. J. Theor. Biol. 2017, 434, 20-33. [CrossRef]

10. Wren, B.W. Microbial Genome Analysis: Insights into Virulence, Host Adaptation and Evolution. Nat. Rev. Genet. 2000, 1, 30-39. [CrossRef] [PubMed]

11. McFall-Ngai, M.J. Identifying "Prime Suspects": Symbioses and the Evolution of Multicellularity. Comp. Biochem. Physiol. B Biochem. Mol. Biol. 2001, 129, 711-723. [CrossRef]

12. Xu, J.; Mahowald, M.A.; Ley, R.E.; Lozupone, C.A.; Hamady, M.; Martens, E.C.; Henrissat, B.; Coutinho, P.M.; Minx, P.; Latreille, P.; et al. Evolution of Symbiotic Bacteria in the Distal Human Intestine. PLoS Biol. 2007, 5, e156. [CrossRef] [PubMed]

13. Lee, S.; La, T.-M.; Lee, H.-J.; Choi, I.-S.; Song, C.-S.; Park, S.-Y.; Lee, J.-B.; Lee, S.-W. Characterization of Microbial Communities in the Chicken Oviduct and the Origin of Chicken Embryo Gut Microbiota. Sci. Rep. 2019, 9, 6838. [CrossRef] [PubMed]

14. Kikuchi, Y.; Hosokawa, T.; Nikoh, N.; Meng, X.-Y.; Kamagata, Y.; Fukatsu, T. Host-Symbiont Co-Speciation and Reductive Genome Evolution in Gut Symbiotic Bacteria of Acanthosomatid Stinkbugs. BMC Biol. 2009, 7, 2. [CrossRef]

15. Tellez, G. Prokaryotes Versus Eukaryotes: Who Is Hosting Whom? Front. Vet. Sci. 2014, 1, 3. [CrossRef] [PubMed]

16. Blaser, M.J. Who Are We? Indigenous Microbes and the Ecology of Human Diseases. EMBO Rep. 2006, 7, 956-960. [CrossRef] [PubMed]

17. Kau, A.L.; Ahern, P.P.; Griffin, N.W.; Goodman, A.L.; Gordon, J.I. Human Nutrition, the Gut Microbiome and the Immune System Nature 2011, 474, 327-336. [CrossRef]

18. Hadrich, D. Microbiome Research Is Becoming the Key to Better Understanding Health and Nutrition. Front. Genet. 2018, 9 , 212 [CrossRef] [PubMed]

19. O'Hara, A.M.; Shanahan, F. The Gut Flora as a Forgotten Organ. EMBO Rep. 2006, 7, 688-693. [CrossRef] [PubMed]

20. Van Der Wielen, P.W.; Biesterveld, S.; Notermans, S.; Hofstra, H.; Urlings, B.A.; van Knapen, F. Role of Volatile Fatty Acids in Development of the Cecal Microflora in Broiler Chickens during Growth. Appl. Environ. MicroBiol. 2000, 66, 2536-2540. [CrossRef]

21. Diaz Carrasco, J.M.; Casanova, N.A.; Fernández Miyakawa, M.E. Microbiota, Gut Health and Chicken Productivity: What Is the Connection? Microorganisms 2019, 7, 374. [CrossRef]

22. Adak, A.; Khan, M.R. An Insight into Gut Microbiota and Its Functionalities. Cell Mol. Life Sci. 2019, 76, 473-493. [CrossRef]

23. Mariat, D.; Firmesse, O.; Levenez, F.; Guimarăes, V.; Sokol, H.; Doré, J.; Corthier, G.; Furet, J.-P. The Firmicutes/Bacteroidetes Ratio of the Human Microbiota Changes with Age. BMC MicroBiol. 2009, 9, 123. [CrossRef] [PubMed]

24. Costea, P.I.; Hildebrand, F.; Arumugam, M.; Bäckhed, F.; Blaser, M.J.; Bushman, F.D.; de Vos, W.M.; Ehrlich, S.D.; Fraser, C.M.; Hattori, M.; et al. Enterotypes in the Landscape of Gut Microbial Community Composition. Nat. MicroBiol. 2018, 3, 8-16. [CrossRef] [PubMed]

25. Turnbaugh, P.J.; Ley, R.E.; Mahowald, M.A.; Magrini, V.; Mardis, E.R.; Gordon, J.I. An Obesity-Associated Gut Microbiome with Increased Capacity for Energy Harvest. Nature 2006, 444, 1027-1031. [CrossRef] [PubMed]

26. Ley, R.E.; Knight, R.; Gordon, J.I. The Human Microbiome: Eliminating the Biomedical/Environmental Dichotomy in Microbial Ecology. Environ. MicroBiol. 2007, 9, 3-4. [CrossRef] [PubMed]

27. Zhao, W.; Wang, Y.; Liu, S.; Huang, J.; Zhai, Z.; He, C.; Ding, J.; Wang, J.; Wang, H.; Fan, W.; et al. The Dynamic Distribution of Porcine Microbiota across Different Ages and Gastrointestinal Tract Segments. PLoS ONE 2015, 10, e0117441. [CrossRef]

28. Subbiah, M.T.R. Nutrigenetics and Nutraceuticals: The next Wave Riding on Personalized Medicine. Transl. Res. 2007, 149, 55-61. [CrossRef] [PubMed]

29. Shehata, A.M.; Paswan, V.K.; Attia, Y.A.; Abdel-Moneim, A.-M.E.; Abougabal, M.S.; Sharaf, M.; Elmazoudy, R.; Alghafari, W.T.; Osman, M.A.; Farag, M.R.; et al. Managing Gut Microbiota through in Ovo Nutrition Influences Early-Life Programming in Broiler Chickens. Animals 2021, 11, 3491. [CrossRef]

30. Sugiharto, S. Role of Nutraceuticals in Gut Health and Growth Performance of Poultry. J. Saudi Soc. Agric. Sci. 2016, 15, 99-111. [CrossRef]

31. Hailu, G.; Boecker, A.; Henson, S.; Cranfield, J. Consumer Valuation of Functional Foods and Nutraceuticals in Canada. A Conjoint Study Using Probiotics. Appetite 2009, 52, 257-265. [CrossRef] [PubMed]

32. Wareth, G.; Sprague, L.D.; Neubauer, H.; Pletz, M.W. Klebsiella Pneumoniae in Germany: An Overview on Spatiotemporal Distribution and Resistance Development in Humans. Ger. J. Microbiol. 2021, 1, 16-25. [CrossRef]

33. Kaonga, N.; Hang'ombe, B.M.; Lupindu, A.M.; Hoza, A.S. Detection of CTX-M-Type Extended-Spectrum Beta-Lactamase Producing Salmonella typhimurium in Commercial Poultry Farms in Copperbelt Province, Zambia. Ger. J. Vet. Res. 2021, 1, 27-34. [CrossRef]

34. Njeru, J. Emerging Carbapenem Resistance in ESKAPE Organisms in Sub-Saharan Africa and the Way Forward. Ger. J. Microbiol. 2021, 1, 3-6. [CrossRef]

35. Ballou, M.A.; Davis, E.M.; Kasl, B.A. Nutraceuticals. Vet. Clin. North Am. Food Anim. Pract. 2019, 35, 507-534. [CrossRef] [PubMed]

36. Metchnikoff, E. The Prolongation of Life. Optimistic Studies; Chalmers, P.M., Ed.; Heinemann: London, UK, 1907.

37. Dhama, K.; Tiwari, R.; Khan, R.U.; Chakrabort, S.; Gopi, M.; Karthik, K.; Saminathan, M.; Desingu, P.A.; Sunkara, L.T. Growth Promoters and Novel Feed Additives Improving Poultry Production and Health, Bioactive Principles and Beneficial Applications: The Trends and Advances-A Review. Int. J. Pharmacol. 2014, 10, 129-159. [CrossRef] 
38. Tlaskalová-Hogenová, H.; Stěpánková, R.; Kozáková, H.; Hudcovic, T.; Vannucci, L.; Tučková, L.; Rossmann, P.; Hrnčíř, T.; Kverka, M.; Zákostelská, Z.; et al. The Role of Gut Microbiota (Commensal Bacteria) and the Mucosal Barrier in the Pathogenesis of Inflammatory and Autoimmune Diseases and Cancer: Contribution of Germ-Free and Gnotobiotic Animal Models of Human Diseases. Cell. Mol. Immunol. 2011, 8, 110-120. [CrossRef] [PubMed]

39. Pourabedin, M.; Zhao, X. Prebiotics and Gut Microbiota in Chickens. FEMS MicroBiol. Lett. 2015, 362, fnv122. [CrossRef]

40. Shang, Y.; Kumar, S.; Oakley, B.; Kim, W.K. Chicken Gut Microbiota: Importance and Detection Technology. Front. Vet. Sci. 2018, 5, 254. [CrossRef]

41. Ulluwishewa, D.; Anderson, R.C.; McNabb, W.C.; Moughan, P.J.; Wells, J.M.; Roy, N.C. Regulation of Tight Junction Permeability by Intestinal Bacteria and Dietary Components. J. Nutr. 2011, 141, 769-776. [CrossRef] [PubMed]

42. Ballard, S.T.; Hunter, J.H.; Taylor, A.E. Regulation of Tight-Junction Permeability During Nutrient Absorption Across the Intestinal Epithelium. Annu. Rev. Nutr. 1995, 15, 35-55. [CrossRef]

43. González-Mariscal, L.; Tapia, R.; Chamorro, D. Crosstalk of Tight Junction Components with Signaling Pathways. Biochim. Biophys. Acta (BBA) Biomembr. 2008, 1778, 729-756. [CrossRef] [PubMed]

44. Harhaj, N.S.; Antonetti, D.A. Regulation of Tight Junctions and Loss of Barrier Function in Pathophysiology. Int. J. Biochem. Cell. Biol. 2004, 36, 1206-1237. [CrossRef] [PubMed]

45. Faralli, A.; Shekarforoush, E.; Ajalloueian, F.; Mendes, A.C.; Chronakis, I.S. In Vitro Permeability Enhancement of Curcumin across Caco-2 Cells Monolayers Using Electrospun Xanthan-Chitosan Nanofibers. Carbohydr. Polym. 2019, 206, 38-47. [CrossRef] [PubMed]

46. Wang, J.; Ghosh, S.S.; Ghosh, S. Curcumin Improves Intestinal Barrier Function: Modulation of Intracellular Signaling, and Organization of Tight Junctions. Am. J. Physiol. Cell. Physiol. 2017, 312, C438-C445. [CrossRef]

47. Baumgard, L.H.; Rhoads, R.P. Effects of Heat Stress on Postabsorptive Metabolism and Energetics. Annu. Rev. Anim. BioSci. 2013, 1,311-337. [CrossRef]

48. Pearce, S.C.; Mani, V.; Weber, T.E.; Rhoads, R.P.; Patience, J.F.; Baumgard, L.H.; Gabler, N.K. Heat Stress and Reduced Plane of Nutrition Decreases Intestinal Integrity and Function in Pigs. J. Anim. Sci. 2013, 91, 5183-5193. [CrossRef]

49. Gilani, S.; Chrystal, P.V.; Barekatain, R. Current Experimental Models, Assessment and Dietary Modulations of Intestinal Permeability in Broiler Chickens. Anim. Nutr. 2021, 7, 801-811. [CrossRef]

50. Kvidera, S.K.; Dickson, M.J.; Abuajamieh, M.; Snider, D.B.; Fernandez, M.V.S.; Johnson, J.S.; Keating, A.F.; Gorden, P.J.; Green, H.B.; Schoenberg, K.M.; et al. Intentionally Induced Intestinal Barrier Dysfunction Causes Inflammation, Affects Metabolism, and Reduces Productivity in Lactating Holstein Cows. J. Dairy Sci. 2017, 100, 4113-4127. [CrossRef]

51. Gilani, S.; Howarth, G.S.; Kitessa, S.M.; Tran, C.D.; Forder, R.E.A.; Hughes, R.J. New Biomarkers for Increased Intestinal Permeability Induced by Dextran Sodium Sulphate and Fasting in Chickens. J. Anim. Physiol. Anim. Nutr. 2017, 101, e237-e245. [CrossRef]

52. Ducatelle, R.; Goossens, E.; De Meyer, F.; Eeckhaut, V.; Antonissen, G.; Haesebrouck, F.; Van Immerseel, F. Biomarkers for Monitoring Intestinal Health in Poultry: Present Status and Future Perspectives. Vet. Res. 2018, 49, 43. [CrossRef]

53. Tellez, G.; Latorre, J.D.; Kuttappan, V.A.; Kogut, M.H.; Wolfenden, A.; Hernandez-Velasco, X.; Hargis, B.M.; Bottje, W.G.; Bielke, L.R.; Faulkner, O.B. Utilization of Rye as Energy Source Affects Bacterial Translocation, Intestinal Viscosity, Microbiota Composition, and Bone Mineralization in Broiler Chickens. Front. Genet. 2014, 5, 339. [CrossRef]

54. Chen, J.; Tellez, G.; Richards, J.D.; Escobar, J. Identification of Potential Biomarkers for Gut Barrier Failure in Broiler Chickens. Front. Vet. Sci. 2015, 2, 14. [CrossRef]

55. Ruff, J.; Tellez, G.; Forga, A.J.; Señas-Cuesta, R.; Vuong, C.N.; Greene, E.S.; Hernandez-Velasco, X.; Uribe, Á.J.; Martínez, B.C.; Angel-Isaza, J.A.; et al. Evaluation of Three Formulations of Essential Oils in Broiler Chickens under Cyclic Heat Stress. Animals 2021, 11, 1084. [CrossRef]

56. Srinivasan, B.; Kolli, A.R.; Esch, M.B.; Abaci, H.E.; Shuler, M.L.; Hickman, J.J. TEER Measurement Techniques for In Vitro Barrier Model Systems. J. Lab. Autom. 2015, 20, 107-126. [CrossRef] [PubMed]

57. Janssen Duijghuijsen, L.M.; Grefte, S.; de Boer, V.C.J.; Zeper, L.; van Dartel, D.A.M.; van der Stelt, I.; Bekkenkamp-Grovenstein, M.; van Norren, K.; Wichers, H.J.; Keijer, J. Mitochondrial ATP Depletion Disrupts Caco-2 Monolayer Integrity and Internalizes Claudin 7. Front. Physiol. 2017, 8, 794. [CrossRef] [PubMed]

58. Xu, J.-X.; Cao, C.-Y.; Sun, Y.-C.; Wang, L.-L.; Li, N.; Xu, S.-W.; Li, J.-L. Effects on Liver Hydrogen Peroxide Metabolism Induced by Dietary Selenium Deficiency or Excess in Chickens. Biol. Trace Elem. Res. 2014, 159, 174-182. [CrossRef]

59. Baxter, M.F.A.; Latorre, J.D.; Dridi, S.; Merino-Guzman, R.; Hernandez-Velasco, X.; Hargis, B.M.; Tellez-Isaias, G. Identification of Serum Biomarkers for Intestinal Integrity in a Broiler Chicken Malabsorption Model. Front. Vet. Sci. 2019, 6, 144. [CrossRef] [PubMed]

60. Windmueller, H.G.; Spaeth, A.E. Source and Fate of Circulating Citrulline. Am. J. Physiol. Endocrinol. Metab. 1981, 241, E473-E480. [CrossRef] [PubMed]

61. Berkeveld, M.; Langendijk, P.; Verheijden, J.H.M.; Taverne, M.A.M.; van Nes, A.; van Haard, P.; Koets, A.P. Citrulline and Intestinal Fatty Acid-Binding Protein: Longitudinal Markers of Postweaning Small Intestinal Function in Pigs? J. Anim. Sci. 2008, 86, 3440-3449. [CrossRef]

62. Iizuka, M. Wound Healing of Intestinal Epithelial Cells. WJG 2011, 17, 2161. [CrossRef] [PubMed] 
63. Staley, M.; Conners, M.G.; Hall, K.; Miller, L.J. Linking Stress and Immunity: Immunoglobulin A as a Non-Invasive Physiological Biomarker in Animal Welfare Studies. Horm. Behav. 2018, 102, 55-68. [CrossRef] [PubMed]

64. Utech, M.; Ivanov, A.I.; Samarin, S.N.; Bruewer, M.; Turner, J.R.; Mrsny, R.J.; Parkos, C.A.; Nusrat, A. Mechanism of IFN- $\gamma$-Induced Endocytosis of Tight Junction Proteins: Myosin II-Dependent Vacuolarization of the Apical Plasma Membrane. MBoC 2005, 16, 5040-5052. [CrossRef]

65. Nava, P.; Koch, S.; Laukoetter, M.G.; Lee, W.Y.; Kolegraff, K.; Capaldo, C.T.; Beeman, N.; Addis, C.; Gerner-Smidt, K.; Neumaier, I.; et al. Interferon- $\gamma$ Regulates Intestinal Epithelial Homeostasis through Converging $\beta$-Catenin Signaling Pathways. Immunity 2010, 32, 392-402. [CrossRef] [PubMed]

66. Awad, W.A.; Ghareeb, K.; Böhm, J. Evaluation of the Chicory Inulin Efficacy on Ameliorating the Intestinal Morphology and Modulating the Intestinal Electrophysiological Properties in Broiler Chickens: Evaluation of the Chicory Inulin Efficacy in Broiler Chickens. J. Anim. Physiol. Anim. Nutr. 2011, 95, 65-72. [CrossRef]

67. Wideman, R.F.; Hamal, K.R.; Stark, J.M.; Blankenship, J.; Lester, H.; Mitchell, K.N.; Lorenzoni, G.; Pevzner, I. A Wire-Flooring Model for Inducing Lameness in Broilers: Evaluation of Probiotics as a Prophylactic Treatment. Poult. Sci. 2012, 91, 870-883. [CrossRef]

68. Wideman, R.F.; Al-Rubaye, A.; Kwon, Y.M.; Blankenship, J.; Lester, H.; Mitchell, K.N.; Pevzner, I.Y.; Lohrmann, T.; Schleifer, J. Prophylactic Administration of a Combined Prebiotic and Probiotic, or Therapeutic Administration of Enrofloxacin, to Reduce the Incidence of Bacterial Chondronecrosis with Osteomyelitis in Broilers. Poult. Sci. 2015, 94, 25-36. [CrossRef]

69. Saleh, M.; Elson, C.O. Experimental Inflammatory Bowel Disease: Insights into the Host-Microbiota Dialog. Immunity 2011, 34, 293-302. [CrossRef]

70. Latorre, J.D.; Hernandez-Velasco, X.; Bielke, L.R.; Vicente, J.L.; Wolfenden, R.; Menconi, A.; Hargis, B.M.; Tellez, G. Evaluation of a Bacillus Direct-Fed Microbial Candidate on Digesta Viscosity, Bacterial Translocation, Microbiota Composition and Bone Mineralisation in Broiler Chickens Fed on a Rye-Based Diet. Br. Poult. Sci. 2015, 56, 723-732. [CrossRef]

71. Baxter, M.F.A.; Merino-Guzman, R.; Latorre, J.D.; Mahaffey, B.D.; Yang, Y.; Teague, K.D.; Graham, L.E.; Wolfenden, A.D.; Hernandez-Velasco, X.; Bielke, L.R.; et al. Optimizing Fluorescein Isothiocyanate Dextran Measurement as a Biomarker in a 24-h Feed Restriction Model to Induce Gut Permeability in Broiler Chickens. Front. Vet. Sci. 2017, 4, 56. [CrossRef]

72. Furuhashi, M.; Hotamisligil, G.S. Fatty Acid-Binding Proteins: Role in Metabolic Diseases and Potential as Drug Targets. Nat. Rev. Drug Discov. 2008, 7, 489-503. [CrossRef] [PubMed]

73. Albala, C.; Santos, J.L.; Cifuentes, M.; Villarroel, A.C.; Lera, L.; Liberman, C.; Angel, B.; Pérez-Bravo, F. Intestinal FABP2 A54T Polymorphism: Association with Insulin Resistance and Obesity in Women. Obes. Res. 2004, 12, 340-345. [CrossRef]

74. Dal Pont, G.C.; Belote, B.L.; Lee, A.; Bortoluzzi, C.; Eyng, C.; Sevastiyanova, M.; Khadem, A.; Santin, E.; Farnell, Y.Z.; Gougoulias, C.; et al. Novel Models for Chronic Intestinal Inflammation in Chickens: Intestinal Inflammation Pattern and Biomarkers. Front. Immunol. 2021, 12, 676628. [CrossRef]

75. Schrezenmeir, J.; de Vrese, M. Probiotics, Prebiotics, and Synbiotics-Approaching a Definition. Am J. Clin. Nutr. 2001, 73, 361S-364S. [CrossRef]

76. Yurong, Y.; Ruiping, S.; Shimin, Z.; Yibao, J. Effect of Probiotics on Intestinal Mucosal Immunity and Ultrastructure of Cecal Tonsils of Chickens. Arch. Anim. Nutr. 2005, 59, 237-246. [CrossRef] [PubMed]

77. Vanderpool, C.; Yan, F.; Polk, D.B. Mechanisms of Probiotic Action: Implications for Therapeutic Applications in Inflammatory Bowel Diseases. Inflamm. Bowel Dis. 2008, 14, 1585-1596. [CrossRef]

78. Prado-Rebolledo, O.F.; de Jesus Delgado-Machuca, J.; Macedo-Barragan, R.J.; Garcia-Márquez, L.J.; Morales-Barrera, J.E.; Latorre, J.D.; Hernandez-Velasco, X.; Tellez, G. Evaluation of a Selected Lactic Acid Bacteria-Based Probiotic on Salmonella enterica Serovar Enteritidis Colonization and Intestinal Permeability in Broiler Chickens. Avian Pathol. 2017, 46, 90-94. [CrossRef] [PubMed]

79. Molinaro, F.; Paschetta, E.; Cassader, M.; Gambino, R.; Musso, G. Probiotics, Prebiotics, Energy Balance, and Obesity: Mechanistic Insights and Therapeutic Implications. Gastroenterol. Clin. North Am. 2012, 41, 843-854. [CrossRef]

80. Higgins, J.P.; Higgins, S.E.; Vicente, J.L.; Wolfenden, A.D.; Tellez, G.; Hargis, B.M. Temporal Effects of Lactic Acid Bacteria Probiotic Culture on Salmonella in Neonatal Broilers. Poult. Sci. 2007, 86, 1662-1666. [CrossRef]

81. Vicente, J.; Wolfenden, A.; Torres-Rodriguez, A.; Higgins, S.; Tellez, G.; Hargis, B. Effect of a Lactobacillus Species-Based Probiotic and Dietary Lactose Prebiotic on Turkey Poult Performance with or Without Salmonella enteritidis Challenge. J. Appl. Poult. Res. 2007, 16, 361-364. [CrossRef]

82. Menconi, A.; Wolfenden, A.D.; Shivaramaiah, S.; Terraes, J.C.; Urbano, T.; Kuttel, J.; Kremer, C.; Hargis, B.M.; Tellez, G. Effect of Lactic Acid Bacteria Probiotic Culture for the Treatment of Salmonella Enterica Serovar Heidelberg in Neonatal Broiler Chickens and Turkey Poults. Poult. Sci. 2011, 90, 561-565. [CrossRef]

83. Higgins, S.E.; Torres-Rodriguez, A.; Vicente, J.L.; Sartor, C.D.; Pixley, C.M.; Nava, G.M.; Tellez, G.; Barton, J.T.; Hargis, B.M. Evaluation of Intervention Strategies for Idiopathic Diarrhea in Commercial Turkey Brooding Houses. J. Appl. Poult. Res. 2005, 14, 345-348. [CrossRef]

84. Torres-Rodriguez, A.; Higgins, S.E.; Vicente, J.L.S.; Wolfenden, A.D.; Gaona-Ramirez, G.; Barton, J.T.; Tellez, G.; Donoghue, A.M.; Hargis, B.M. Effect of Lactose as a Prebiotic on Turkey Body Weight Under Commercial Conditions. J. Appl. Poult. Res. 2007, 16, 635-641. [CrossRef]

85. Higgins, S.E.; Wolfenden, A.D.; Tellez, G.; Hargis, B.M.; Porter, T.E. Transcriptional Profiling of Cecal Gene Expression in Probioticand Salmonella-Challenged Neonatal Chicks. Poult Sci. 2011, 90, 901-913. [CrossRef] [PubMed] 
86. Tellez-Isaias, G.; Vuong, C.N.; Graham, B.D.; Selby, C.M.; Graham, L.E.; Señas-Cuesta, R.; Barros, T.L.; Beer, L.C.; Coles, M.E.; Forga, A.J.; et al. Developing Probiotics, Prebiotics, and Organic Acids to Control Salmonella Spp. in Commercial Turkeys at the University of Arkansas, USA. Ger. J. Vet. Res. 2021, 1, 7-12. [CrossRef]

87. Vreeland, R.H.; Rosenzweig, W.D.; Powers, D.W. Isolation of a 250 Million-Year-Old Halotolerant Bacterium from a Primary Salt Crystal. Nature 2000, 407, 897-900. [CrossRef]

88. Hong, H.A.; Duc, L.H.; Cutting, S.M. The Use of Bacterial Spore Formers as Probiotics. FEMS MicroBiol. Rev. 2005, 29 , 813-835. [CrossRef]

89. Shivaramaiah, S.; Pumford, N.R.; Morgan, M.J.; Wolfenden, R.E.; Wolfenden, A.D.; Torres-Rodríguez, A.; Hargis, B.M.; Téllez, G. Evaluation of Bacillus Species as Potential Candidates for Direct-Fed Microbials in Commercial Poultry. Poult. Sci. 2011, 90, 1574-1580. [CrossRef]

90. Wolfenden, R.E.; Pumford, N.R.; Morgan, M.J.; Shivaramaiah, S.; Wolfenden, A.D.; Pixley, C.M.; Green, J.; Tellez, G.; Hargis, B.M. Evaluation of Selected Direct-Fed Microbial Candidates on Live Performance and Salmonella Reduction in Commercial Turkey Brooding Houses. Poult. Sci. 2011, 90, 2627-2631. [CrossRef]

91. Wolfenden, R.E.; Pumford, N.R.; Morgan, M.J.; Shivaramai, S.; Wolfenden, A.D.; Tellez, G.; Hargis, B.M. Evaluation of a Screening and Selection Method for Bacillus Isolates for Use as Effective Direct-Fed Microbials in Commercial Poultry. Int. J. Poult. Sci. 2010, 9, 317-323. [CrossRef]

92. Sen, S.; Ingale, S.L.; Kim, Y.W.; Kim, J.S.; Kim, K.H.; Lohakare, J.D.; Kim, E.K.; Kim, H.S.; Ryu, M.H.; Kwon, I.K.; et al. Effect of Supplementation of Bacillus Subtilis LS 1-2 to Broiler Diets on Growth Performance, Nutrient Retention, Caecal Microbiology and Small Intestinal Morphology. Res. Vet. Sci. 2012, 93, 264-268. [CrossRef] [PubMed]

93. Latorre, J.D.; Hernandez-Velasco, X.; Kallapura, G.; Menconi, A.; Pumford, N.R.; Morgan, M.J.; Layton, S.L.; Bielke, L.R.; Hargis, B.M.; Téllez, G. Evaluation of Germination, Distribution, and Persistence of Bacillus subtilis Spores through the Gastrointestinal Tract of Chickens. Poult. Sci. 2014, 93, 1793-1800. [CrossRef]

94. Bedford, M.R.; Schulze, H. Exogenous Enzymes for Pigs and Poultry. Nutr. Res. Rev. 1998, 11, 91-114. [CrossRef]

95. Esteve-Garcia, E.; Brufau, J.; Pérez-Vendrell, A.; Miquel, A.; Duven, K. Bioefficacy of Enzyme Preparations Containing BetaGlucanase and Xylanase Activities in Broiler Diets Based on Barley or Wheat, in Combination with Flavomycin. Poult. Sci. 1997, 76, 1728-1737. [CrossRef] [PubMed]

96. Latorre, J.D.; Hernandez-Velasco, X.; Kogut, M.H.; Vicente, J.L.; Wolfenden, R.; Wolfenden, A.; Hargis, B.M.; Kuttappan, V.A.; Tellez, G. Role of a Bacillus Subtilis Direct-Fed Microbial on Digesta Viscosity, Bacterial Translocation, and Bone Mineralization in Turkey Poults Fed with a Rye-Based Diet. Front. Vet. Sci. 2014, 1, 26. [CrossRef] [PubMed]

97. Adhikari, B.; Hernandez-Patlan, D.; Solis-Cruz, B.; Kwon, Y.M.; Arreguin, M.A.; Latorre, J.D.; Hernandez-Velasco, X.; Hargis, B.M.; Tellez-Isaias, G. Evaluation of the Antimicrobial and Anti-Inflammatory Properties of Bacillus-DFM $\left(\mathrm{Norum}^{\mathrm{TM}}\right)$ in Broiler Chickens Infected with Salmonella Enteritidis. Front. Vet. Sci. 2019, 6, 282. [CrossRef]

98. Solis-Cruz, B.; Hernandez-Patlan, D.; Petrone, V.M.; Pontin, K.P.; Latorre, J.D.; Beyssac, E.; Hernandez-Velasco, X.; Merino-Guzman, R.; Arreguin, M.A.; Hargis, B.M.; et al. Evaluation of a Bacillus -Based Direct-Fed Microbial on Aflatoxin B1 Toxic Effects, Performance, Immunologic Status, and Serum Biochemical Parameters in Broiler Chickens. Avian Dis. 2019, 63, 659-669. [CrossRef]

99. Black, S.; Fahrenholz, A.; Grimes, J.L. The effect of a direct-fed microbial and dietary fat inclusion on performance and energy metabolism in broiler chicks and turkey poults. Ger. J. Vet. Res. 2021, 1, 1-10. [CrossRef]

100. Liu, X.; Cao, S.; Zhang, X. Modulation of Gut Microbiota-Brain Axis by Probiotics, Prebiotics, and Diet. J. Agric. Food Chem. 2015, 63, 7885-7895. [CrossRef]

101. Hamilton-Miller, J.M.T. Probiotics and Prebiotics in the Elderly. Postgrad. Med. J. 2004, 80, 447-451. [CrossRef]

102. Hedin, C.; Whelan, K.; Lindsay, J.O. Evidence for the Use of Probiotics and Prebiotics in Inflammatory Bowel Disease: A Review of Clinical Trials. Proc. Nutr. Soc. 2007, 66, 307-315. [CrossRef] [PubMed]

103. Everard, A.; Lazarevic, V.; Derrien, M.; Girard, M.; Muccioli, G.G.; Muccioli, G.M.; Neyrinck, A.M.; Possemiers, S.; Van Holle, A.; François, P.; et al. Responses of Gut Microbiota and Glucose and Lipid Metabolism to Prebiotics in Genetic Obese and Diet-Induced Leptin-Resistant Mice. Diabetes 2011, 60, 2775-2786. [CrossRef] [PubMed]

104. Ducatelle, R.; Eeckhaut, V.; Haesebrouck, F.; Van Immerseel, F. A Review on Prebiotics and Probiotics for the Control of Dysbiosis: Present Status and Future Perspectives. Animal 2015, 9, 43-48. [CrossRef] [PubMed]

105. Ajuwon, K.M. Toward a Better Understanding of Mechanisms of Probiotics and Prebiotics Action in Poultry Species. J. Appl. Poult. Res. 2016, 25, 277-283. [CrossRef]

106. Collins, M.D.; Gibson, G.R. Probiotics, Prebiotics, and Synbiotics: Approaches for Modulating the Microbial Ecology of the Gut. Am. J. Clin. Nutr. 1999, 69, 1052S-1057S. [CrossRef]

107. Pandey, K.R.; Naik, S.R.; Vakil, B.V. Probiotics, Prebiotics and Synbiotics- a Review. J. Food Sci. Technol. 2015, 52, 7577-7587. [CrossRef]

108. Van den Broek, L.A.M.; Hinz, S.W.A.; Beldman, G.; Vincken, J.-P.; Voragen, A.G.J. Bifidobacterium Carbohydrases-Their Role in Breakdown and Synthesis of (Potential) Prebiotics. Mol. Nutr. Food Res. 2008, 52, 146-163. [CrossRef]

109. Dhama, K.; Mahendran, M.; Tomar, S.; Chauhan, R. Beneficial Effects of Probiotics and Prebiotics in Livestock and Poultry: The Current Perspectives. Intas. Polivet. 2008, 9, 1-12. 
110. Janssens, G.P.J.; Millet, S.; Van Immerseel, F.; De Buck, J.; Hesta, M. The Impact of Prebiotics and Salmonellosis on Apparent Nutrient Digestibility and Salmonella typhimurium Var. Copenhagen Excretion in Adult Pigeons (Columba Livia Domestica). Poult. Sci. 2004, 83, 1884-1890. [CrossRef]

111. Parracho, H.; McCartney, A.L.; Gibson, G.R. Probiotics and Prebiotics in Infant Nutrition. Proc. Nutr. Soc. 2007, 66, 405-411. [CrossRef]

112. Teitelbaum, J.E.; Walker, W.A. Nutritional Impact of Pre- and Probiotics as Protective Gastrointestinal Organisms. Annu. Rev. Nutr. 2002, 22, 107-138. [CrossRef] [PubMed]

113. Yalcin, S.; Ilyas, O.; Handan, E. Effects of dietary yeast cell wall on performance, egg quality and humoral immune response in laying hens. Ank. Üniv. Vet. Fakültesi Derg. 2014, 61, 289-294. [CrossRef]

114. Harms, R.H.; Miles, R.D. Influence of Fermacto on the Performance of Laying Hens When Fed Diets with Different Levels of Methionine. Poult. Sci. 1988, 67, 842-844. [CrossRef] [PubMed]

115. Torres-Rodriguez, A.; Sartor, C.; Higgins, S.E.; Wolfenden, A.D.; Bielke, L.R.; Pixley, C.M.; Sutton, L.; Tellez, G.; Hargis, B.M. Effect of Aspergillus Meal Prebiotic (Fermacto) on Performance of Broiler Chickens in the Starter Phase and Fed Low Protein Diets. J. Appl. Poult. Res. 2005, 14, 665-669. [CrossRef]

116. Uchima, C.A.; Tokuda, G.; Watanabe, H.; Kitamoto, K.; Arioka, M. Heterologous Expression and Characterization of a GlucoseStimulated $\beta$-Glucosidase from the Termite Neotermes Koshunensis in Aspergillus Oryzae. Appl. MicroBiol. Biotechnol. 2011, 89, 1761-1771. [CrossRef]

117. Hernandez-Patlan, D.; Solis-Cruz, B.; Hargis, B.M.; Tellez, G. Chitoneous Materials for Control of Foodborne Pathogens and Mycotoxins in Poultry. In Chitin-Chitosan-Myriad Functionalities in Science and Technology; Dongre, R.S., Ed.; InTech: London, UK, 2018; ISBN 978-1-78923-406-0.

118. Jonker, D.; Kuper, C.F.; Maquet, V.; Nollevaux, G.; Gautier, S. Subchronic (13-Week) Oral Toxicity Study in Rats with Fungal Chitin-Glucan from Aspergillus Niger. Food Chem. Toxicol. 2010, 48, 2695-2701. [CrossRef] [PubMed]

119. Hooge, D.M.; Sims, M.D.; Sefton, A.E.; Spring, P.; Connolly, A. Effect of Dietary Mannan Oligosaccharide, With or Without Bacitracin or Virginiamycin, on Live Performance of Broiler Chickens at Relatively High Stocking Density on New Litter. J. Appl. Poult. Res. 2003, 12, 461-467. [CrossRef]

120. Kim, W.K.; Donalson, L.M.; Mitchell, A.D.; Kubena, L.F.; Nisbet, D.J.; Ricke, S.C. Effects of Alfalfa and Fructooligosaccharide on Molting Parameters and Bone Qualities Using Dual Energy X-ray Absorptiometry and Conventional Bone Assays. Poult. Sci. 2006, 85, 15-20. [CrossRef]

121. Tellez, G.; Nava, G.M.; Vicente, J.L.; De Frances, M.; Morales, E.J.; Prado, O.; Terraes, J.C.; Hargis, B.M. Evaluation of Dietary Aspergillus Meal on Intestinal Morphometry in Turkey Poults. Int. J. Poult. Sci. 2010, 9, 875-878. [CrossRef]

122. Amirdahri, S.; Janmohammadi, H.; Taghizadeh, A.; Rafat, S.A. Effect of Dietary Aspergillus Meal Prebiotic on Growth Performance, Carcass Characteristics, Nutrient Digestibility, and Serum Lipid Profile in Broiler Chick Low-Protein Diets. Turk. J. Vet. Anim. Sci. 2012, 36. [CrossRef]

123. Reginatto, A.R.; Menconi, A.; Londero, A.; Lovato, M.; Rosa, A.P.; Shivaramai, S.; Wolfenden, A.D.; Huff, W.E.; Huff, G.R.; Rath, N.C.; et al. Effects of Dietary Aspergillus Meal Prebiotic on Turkey Poults Production Parameters and Bone Qualities. Int. J. Poult. Sci. 2011, 10, 496-499. [CrossRef]

124. Scholz-Ahrens, K.E.; Ade, P.; Marten, B.; Weber, P.; Timm, W.; Açil, Y.; Glüer, C.-C.; Schrezenmeir, J. Prebiotics, Probiotics, and Synbiotics Affect Mineral Absorption, Bone Mineral Content, and Bone Structure. J. Nutr. 2007, 137, 838S-846S. [CrossRef] [PubMed]

125. Van Immerseel, F.; De Buck, J.; De Smet, I.; Mast, J.; Haesebrouck, F.; Ducatelle, R. Dynamics of Immune Cell Infiltration in the Caecal Lamina Propria of Chickens after Neonatal Infection with a Salmonella enteritidis Strain. Dev. Comp. Immunol. 2002, 26, 355-364. [CrossRef]

126. Burkholder, K.M.; Thompson, K.L.; Einstein, M.E.; Applegate, T.J.; Patterson, J.A. Influence of Stressors on Normal Intestinal Microbiota, Intestinal Morphology, and Susceptibility to Salmonella enteritidis Colonization in Broilers. Poult. Sci. 2008, 87, 1734-1741. [CrossRef] [PubMed]

127. Filipkowska, U.; Jóźwiak, T.; Szymczyk, P. Application of cross-linked chitosan for phosphate removal from aqueous solutions. Prog. Chem. Appl. Chitin Its Deriv. Volume XIX 2014, 19, 5-14. [CrossRef]

128. Ravi Kumar, M.N.V. A Review of Chitin and Chitosan Applications. React. Funct. Polym. 2000, 46, 1-27. [CrossRef]

129. Londero, A.; Menconi, A.; Reginatto, A.R.; Bacocina, I.; Wolfenden, A.; Shivaramai, S.; Hargis, B.M.; Tellez, G. Effect of an Aspergillus Meal Prebiotic on Salmonella Infection in Turkeys and Broiler Chickens. Int. J. Poult. Sci. 2011, 10, 946-951. [CrossRef]

130. Yalçin, S.; Yalçin, S.; Eser, H.; Şahin, A.; Yalçin, S.S.; Güçer, Ş. Effects of Dietary Yeast Cell Wall Supplementation on Performance, Carcass Characteristics, Antibody Production and Histopathological Changes in Broilers. Kafkas Univ. Vet. Fak. Derg. 2014, 20. [CrossRef]

131. Awad, W.A.; Ghareeb, K.; Abdel-Raheem, S.; Böhm, J. Effects of Dietary Inclusion of Probiotic and Synbiotic on Growth Performance, Organ Weights, and Intestinal Histomorphology of Broiler Chickens. Poult. Sci. 2009, 88, 49-56. [CrossRef]

132. Maiorano, G.; Sobolewska, A.; Cianciullo, D.; Walasik, K.; Elminowska-Wenda, G.; Slawinska, A.; Tavaniello, S.; Zylinska, J.; Bardowski, J.; Bednarczyk, M. Influence of in Ovo Prebiotic and Synbiotic Administration on Meat Quality of Broiler Chickens. Poult. Sci. 2012, 91, 2963-2969. [CrossRef] 
133. Yang, X.J.; Li, W.L.; Feng, Y.; Yao, J.H. Effects of Immune Stress on Growth Performance, Immunity, and Cecal Microflora in Chickens. Poult. Sci. 2011, 90, 2740-2746. [CrossRef] [PubMed]

134. Dimitrov, D.V. The Human Gutome: Nutrigenomics of the Host-Microbiome Interactions. OMICS 2011, 15, 419-430. [CrossRef] [PubMed]

135. Tellez, G.; Higgins, S.E.; Donoghue, A.M.; Hargis, B.M. Digestive Physiology and the Role of Microorganisms. J. Appl. Poult. Res. 2006, 15, 136-144. [CrossRef]

136. Weiss, A.S.; Burrichter, A.G.; Durai Raj, A.C.; von Strempel, A.; Meng, C.; Kleigrewe, K.; Münch, P.C.; Rössler, L.; Huber, C.; Eisenreich, W.; et al. In Vitro Interaction Network of a Synthetic Gut Bacterial Community. ISME J. 2021, 1-15. [CrossRef]

137. Plöger, S.; Stumpff, F.; Penner, G.B.; Schulzke, J.-D.; Gäbel, G.; Martens, H.; Shen, Z.; Günzel, D.; Aschenbach, J.R. Microbial Butyrate and Its Role for Barrier Function in the Gastrointestinal Tract. Ann. N. Y. Acad. Sci. 2012, 1258, 52-59. [CrossRef] [PubMed]

138. Braniste, V.; Al-Asmakh, M.; Kowal, C.; Anuar, F.; Abbaspour, A.; Tóth, M.; Korecka, A.; Bakocevic, N.; Ng, L.G.; Guan, N.L.; et al. The Gut Microbiota Influences Blood-Brain Barrier Permeability in Mice. Sci. Transl. Med. 2014, 6, 263ra158. [CrossRef]

139. Shen, J.; Obin, M.S.; Zhao, L. The Gut Microbiota, Obesity and Insulin Resistance. Mol. Aspects Med. 2013, 34, 39-58. [CrossRef] [PubMed]

140. Begley, M.; Gahan, C.G.M.; Hill, C. The Interaction between Bacteria and Bile. FEMS MicroBiol. Rev. 2005, 29, 625-651. [CrossRef]

141. Hofmann, A.F. Bile Acids: The Good, the Bad, and the Ugly. News Physiol. Sci. 1999, 14, 24-29. [CrossRef]

142. Calik, A.; Ceylan, A.; Ekim, B.; Adabi, S.G.; Dilber, F.; Bayraktaroglu, A.G.; Tekinay, T.; Özen, D.; Sacakli, P. The Effect of Intra-Amniotic and Posthatch Dietary Synbiotic Administration on the Performance, Intestinal Histomorphology, Cecal Microbial Population, and Short-Chain Fatty Acid Composition of Broiler Chickens. Poult. Sci. 2017, 96, 169-183. [CrossRef]

143. Montagne, L.; Piel, C.; Lallès, J.P. Effect of Diet on Mucin Kinetics and Composition: Nutrition and Health Implications. Nutr. Rev. 2004, 62, 105-114. [CrossRef]

144. Schippa, S.; Conte, M. Dysbiotic Events in Gut Microbiota: Impact on Human Health. Nutrients 2014, 6, 5786-5805. [CrossRef] [PubMed]

145. EC (European Commission). Regulation 1831 of the European Parliament and of the Council of 22 September 2003 on Additives for Use in Animal Nutrition. Off. J. Eur. Union L. 2003, 268, 29-43.

146. Giannenas, I.; Florou-Paneri, P.; Papazahariadou, M.; Christaki, E.; Botsoglou, N.A.; Spais, A.B. Effect of Dietary Supplementation with Oregano Essential Oil on Performance of Broilers after Experimental Infection with Eimeria tenella. Arch. Anim. Nutr. 2003, 57, 99-106. [CrossRef] [PubMed]

147. Isabel, B.; Santos, Y. Effects of Dietary Organic Acids and Essential Oils on Growth Performance and Carcass Characteristics of Broiler Chickens. J. Appl. Poult. Res. 2009, 18, 472-476. [CrossRef]

148. Jamroz, D.; Wiliczkiewicz, A.; Wertelecki, T.; Orda, J.; Skorupińska, J. Use of Active Substances of Plant Origin in Chicken Diets Based on Maize and Locally Grown Cereals. Br. Poult. Sci. 2005, 46, 485-493. [CrossRef]

149. McReynolds, J.; Waneck, C.; Byrd, J.; Genovese, K.; Duke, S.; Nisbet, D. Efficacy of Multistrain Direct-Fed Microbial and Phytogenetic Products in Reducing Necrotic Enteritis in Commercial Broilers. Poult. Sci. 2009, 88, 2075-2080. [CrossRef]

150. Murugesan, G.R.; Syed, B.; Haldar, S.; Pender, C. Phytogenic Feed Additives as an Alternative to Antibiotic Growth Promoters in Broiler Chickens. Front. Vet. Sci. 2015, 2, 21. [CrossRef]

151. Yener, Y.; Yalçin, S.; Çolpan, İ. Effects of Dietary Supplementation of Red Ginseng Root Powder on Performance, Immune System, Cecal Microbial Population and Some Blood Parameters in Broilers. Ank. Üniv. Vet. Fakültesi Derg. 2020, 68, 137-145. [CrossRef]

152. Mathe, A. Essential Oils: Basic and Applied Research. Allured Publishing Corporation, Carol Stream. In Essential Oils as Phytogenic Feed Additives; Allured Publishing Corporation: Carol Stream, IL, USA, 2007; pp. 315-325.

153. Salaheen, S.; Kim, S.-W.; Haley, B.J.; Van Kessel, J.A.S.; Biswas, D. Alternative Growth Promoters Modulate Broiler Gut Microbiome and Enhance Body Weight Gain. Front. Microbiol. 2017, 8, 2088. [CrossRef]

154. Li, Y.; Fu, X.; Ma, X.; Geng, S.; Jiang, X.; Huang, Q.; Hu, C.; Han, X. Intestinal Microbiome-Metabolome Responses to Essential Oils in Piglets. Front. Microbiol. 2018, 9, 1988. [CrossRef] [PubMed]

155. Díaz Carrasco, J.M.; Redondo, E.A.; Pin Viso, N.D.; Redondo, L.M.; Farber, M.D.; Fernández Miyakawa, M.E. Tannins and Bacitracin Differentially Modulate Gut Microbiota of Broiler Chickens. BioMed Res. Int. 2018, 2018, 1-11. [CrossRef] [PubMed]

156. Jha, R.; Berrocoso, J.D. Review: Dietary Fiber Utilization and Its Effects on Physiological Functions and Gut Health of Swine. Animal 2015, 9, 1441-1452. [CrossRef] [PubMed]

157. Schokker, D.; Jansman, A.J.M.; Veninga, G.; de Bruin, N.; Vastenhouw, S.A.; de Bree, F.M.; Bossers, A.; Rebel, J.M.J.; Smits, M.A. Perturbation of Microbiota in One-Day Old Broiler Chickens with Antibiotic for 24 Hours Negatively Affects Intestinal Immune Development. BMC Genom. 2017, 18, 241. [CrossRef] [PubMed]

158. Mathlouthi, N.; Mallet, S.; Saulnier, L.; Quemener, B.; Larbier, M. Effects of Xylanase and?-Glucanase Additionon Performance, Nutrient Digestibility and Physico-Chemical Conditions in the Small Intestine Contents and Caecal Microflora of Broiler Chickens Feda Wheat and Barley-Based Diet. Anim. Res. 2002, 51, 395-406. [CrossRef]

159. Cherbut, C. Motor Effects of Short-Chain Fatty Acids and Lactate in the Gastrointestinal Tract. Proc. Nutr. Soc. 2003, 62, 95-99. [CrossRef]

160. Arumugam, M.; Raes, J.; Pelletier, E.; Le Paslier, D.; Yamada, T.; Mende, D.R.; Fernandes, G.R.; Tap, J.; Bruls, T.; Batto, J.-M.; et al. Enterotypes of the Human Gut Microbiome. Nature 2011, 473, 174-180. [CrossRef] 
161. Xu, X.; Yi, H.; Wu, J.; Kuang, T.; Zhang, J.; Li, Q.; Du, H.; Xu, T.; Jiang, G.; Fan, G. Therapeutic Effect of Berberine on Metabolic Diseases: Both Pharmacological Data and Clinical Evidence. Biomed. Pharmacother. 2021, 133, 110984. [CrossRef] [PubMed]

162. Chen, W.; Miao, Y.-Q.; Fan, D.-J.; Yang, S.-S.; Lin, X.; Meng, L.-K.; Tang, X. Bioavailability Study of Berberine and the Enhancing Effects of TPGS on Intestinal Absorption in Rats. AAPS PharmSciTech 2011, 12, 705-711. [CrossRef]

163. Wang, Y.; Tong, Q.; Shou, J.-W.; Zhao, Z.-X.; Li, X.-Y.; Zhang, X.-F.; Ma, S.-R.; He, C.-Y.; Lin, Y.; Wen, B.-Y.; et al. Gut MicrobiotaMediated Personalized Treatment of Hyperlipidemia Using Berberine. Theranostics 2017, 7, 2443-2451. [CrossRef]

164. Zhang, H.; Wei, J.; Xue, R.; Wu, J.-D.; Zhao, W.; Wang, Z.-Z.; Wang, S.-K.; Zhou, Z.-X.; Song, D.-Q.; Wang, Y.-M.; et al. Berberine Lowers Blood Glucose in Type 2 Diabetes Mellitus Patients through Increasing Insulin Receptor Expression. Metabolism 2010, 59, 285-292. [CrossRef] [PubMed]

165. Takahara, M.; Takaki, A.; Hiraoka, S.; Adachi, T.; Shimomura, Y.; Matsushita, H.; Nguyen, T.T.T.; Koike, K.; Ikeda, A.; Takashima, S.; et al. Berberine Improved Experimental Chronic Colitis by Regulating Interferon- $\gamma$ - and IL-17A-Producing Lamina Propria CD4+ T Cells through AMPK Activation. Sci. Rep. 2019, 9, 11934. [CrossRef] [PubMed]

166. Zeng, Q.; Deng, H.; Li, Y.; Fan, T.; Liu, Y.; Tang, S.; Wei, W.; Liu, X.; Guo, X.; Jiang, J.; et al. Berberine Directly Targets the NEK7 Protein to Block the NEK7-NLRP3 Interaction and Exert Anti-Inflammatory Activity. J. Med. Chem. 2021, 64, 768-781. [CrossRef]

167. Ilyas, Z.; Perna, S.; Al-thawadi, S.; Alalwan, T.A.; Riva, A.; Petrangolini, G.; Gasparri, C.; Infantino, V.; Peroni, G.; Rondanelli, M. The Effect of Berberine on Weight Loss in Order to Prevent Obesity: A Systematic Review. Biomed. Pharmacother. 2020, $127,110137$. [CrossRef]

168. Ke, X.; Huang, Y.; Li, L.; Xin, F.; Xu, L.; Zhang, Y.; Zeng, Z.; Lin, F.; Song, Y. Berberine Attenuates Arterial Plaque Formation in Atherosclerotic Rats with Damp-Heat Syndrome via Regulating Autophagy. DDDT 2020, 14, 2449-2460. [CrossRef]

169. Tan, W.; Wang, Y.; Wang, K.; Wang, S.; Liu, J.; Qin, X.; Dai, Y.; Wang, X.; Gao, X. Improvement of Endothelial Dysfunction of Berberine in Atherosclerotic Mice and Mechanism Exploring through TMT-Based Proteomics. Oxid. Med. Cell. Longev. 2020, 2020, 1-22. [CrossRef] [PubMed]

170. Yu, Y.; Zhang, M.; Hu, Y.; Zhao, Y.; Teng, F.; Lv, X.; Li, J.; Zhang, Y.; Hatch, G.M.; Chen, L. Increased Bioavailable Berberine Protects Against Myocardial Ischemia Reperfusion Injury Through Attenuation of NFkB and JNK Signaling Pathways. Int. Heart J. 2018, 59, 1378-1388. [CrossRef] [PubMed]

171. Gu, L.; Li, N.; Gong, J.; Li, Q.; Zhu, W.; Li, J. Berberine Ameliorates Intestinal Epithelial Tight-Junction Damage and downRegulates Myosin Light Chain Kinase Pathways in a Mouse Model of Endotoxinemia. J. Infect. Dis. 2011, 203, 1602-1612. [CrossRef]

172. Gong, J.; Hu, M.; Huang, Z.; Fang, K.; Wang, D.; Chen, Q.; Li, J.; Yang, D.; Zou, X.; Xu, L.; et al. Berberine Attenuates Intestinal Mucosal Barrier Dysfunction in Type 2 Diabetic Rats. Front. Pharmacol. 2017, 8, 42. [CrossRef]

173. Gu, L.; Li, N.; Li, Q.; Zhang, Q.; Wang, C.; Zhu, W.; Li, J. The Effect of Berberine in Vitro on Tight Junctions in Human Caco-2 Intestinal Epithelial Cells. Fitoterapia 2009, 80, 241-248. [CrossRef]

174. Li, N.; Gu, L.; Qu, L.; Gong, J.; Li, Q.; Zhu, W.; Li, J. Berberine Attenuates Pro-Inflammatory Cytokine-Induced Tight Junction Disruption in an in Vitro Model of Intestinal Epithelial Cells. Eur. J. Pharm. Sci. 2010, 40, 1-8. [CrossRef] [PubMed]

175. Fernandez, C.P.; Afrin, F.; Flores, R.A.; Kim, W.H.; Jeong, J.; Kim, S.; Chang, H.H.; Lillehoj, H.S.; Min, W. Downregulation of Inflammatory Cytokines by Berberine Attenuates Riemerella anatipestifer Infection in Ducks. Dev. Comp. Immunol. 2017, 77, 121-127. [CrossRef] [PubMed]

176. Habtemariam, S. Berberine Pharmacology and the Gut Microbiota: A Hidden Therapeutic Link. Pharmacol. Res. 2020, 155, 104722. [CrossRef] [PubMed]

177. Lyu, Y.; Lin, L.; Xie, Y.; Li, D.; Xiao, M.; Zhang, Y.; Cheung, S.C.K.; Shaw, P.C.; Yang, X.; Chan, P.K.S.; et al. Blood-Glucose-Lowering Effect of Coptidis Rhizoma Extracts from Different Origins via Gut Microbiota Modulation in Db/Db Mice. Front. Pharmacol. 2021, 12, 684358. [CrossRef]

178. Zhu, C.; Huang, K.; Bai, Y.; Feng, X.; Gong, L.; Wei, C.; Huang, H.; Zhang, H. Dietary Supplementation with Berberine Improves Growth Performance and Modulates the Composition and Function of Cecal Microbiota in Yellow-Feathered Broilers. Poult. Sci. 2021, 100, 1034-1048. [CrossRef]

179. Xiang Yu, D.; He, Z.; Pouton, C.; Hoerr, F.J.; Xiao, Z.C. Target Animal Safety and Residual Study for Berberine and Other Phytogenic Compounds in Broiler Chickens. Arch. Clin. MicroBiol. 2017, 8, 69. [CrossRef]

180. Malik, T.A.; Kamili, A.N.; Chishti, M.Z.; Tanveer, S.; Ahad, S.; Johri, R.K. Synergistic Approach for Treatment of Chicken Coccidiosis Using Berberine-A Plant Natural Product. Microb. Pathog. 2016, 93, 56-62. [CrossRef]

181. Yang, L.; Liu, G.; Liang, X.; Wang, M.; Zhu, X.; Luo, Y.; Shang, Y.; Yang, J.; Zhou, P.; Gu, X. Effects of Berberine on the Growth Performance, Antioxidative Capacity and Immune Response to Lipopolysaccharide Challenge in Broilers. Anim. Sci. J. 2019, 90, 1229-1238. [CrossRef]

182. Shen, Y.B.; Piao, X.S.; Kim, S.W.; Wang, L.; Liu, P. The Effects of Berberine on the Magnitude of the Acute Inflammatory Response Induced by Escherichia Coli Lipopolysaccharide in Broiler Chickens. Poult. Sci. 2010, 89, 13-19. [CrossRef]

183. Zhang, Y.; Guo, L.; Huang, J.; Sun, Y.; He, F.; Zloh, M.; Wang, L. Inhibitory Effect of Berberine on Broiler P-Glycoprotein Expression and Function: In Situ and In Vitro Studies. IJMS 2019, 20, 1966. [CrossRef]

184. Frank, M.B.; Yang, Q.; Osban, J.; Azzarello, J.T.; Saban, M.R.; Saban, R.; Ashley, R.A.; Welter, J.C.; Fung, K.-M.; Lin, H.-K. Frankincense Oil Derived from Boswellia Carteri Induces Tumor Cell Specific Cytotoxicity. BMC Complement. Altern. Med. 2009, 9, 6. [CrossRef] 
185. Poeckel, D.; Werz, O. Boswellic Acids: Biological Actions and Molecular Targets. Curr. Med. Chem. 2006, 13, 3359-3369. [CrossRef]

186. Anthoni, C.; Laukoetter, M.G.; Rijcken, E.; Vowinkel, T.; Mennigen, R.; Müller, S.; Senninger, N.; Russell, J.; Jauch, J.; Bergmann, J.; et al. Mechanisms Underlying the Anti-Inflammatory Actions of Boswellic Acid Derivatives in Experimental Colitis. Am. J. Physiol. Gastrointest. Liver Physiol. 2006, 290, G1131-G1137. [CrossRef] [PubMed]

187. Ammon, H.P.T. Modulation of the Immune System by Boswellia Serrata Extracts and Boswellic Acids. Phytomedicine 2010, 17, 862-867. [CrossRef] [PubMed]

188. Abdel-Tawab, M.; Werz, O.; Schubert-Zsilavecz, M. Boswellia serrata: An Overall Assessment of in Vitro, Preclinical, Pharmacokinetic and Clinical Data. Clin. Pharmacokinet. 2011, 50, 349-369. [CrossRef] [PubMed]

189. Catanzaro, D.; Rancan, S.; Orso, G.; Dall'Acqua, S.; Brun, P.; Giron, M.C.; Carrara, M.; Castagliuolo, I.; Ragazzi, E.; Caparrotta, L.; et al. Boswellia Serrata Preserves Intestinal Epithelial Barrier from Oxidative and Inflammatory Damage. PLoS ONE 2015, 10, e0125375. [CrossRef]

190. Ismail, I.E.; Abdelnour, S.A.; Shehata, S.A.; Abd El-Hack, M.E.; El-Edel, M.A.; Taha, A.E.; Schiavitto, M.; Tufarelli, V. Effect of Dietary Boswellia Serrata Resin on Growth Performance, Blood Biochemistry, and Cecal Microbiota of Growing Rabbits. Front. Vet. Sci. 2019, 6, 471. [CrossRef]

191. Mohamed, S.H.; Attia, A.I.; Reda, F.M.; Abd El-Hack, M.E.; Ismail, I.E. Impacts of Dietary Supplementation of Boswellia Serrata on Growth, Nutrients Digestibility, Immunity, Antioxidant Status, Carcase Traits and Caecum Microbiota of Broilers. Ital. J. Anim. Sci. 2021, 20, 205-214. [CrossRef]

192. Al-Yasiry, A.R.M.; Kiczorowska, B.; Samolińska, W.; Kowalczuk-Vasilev, E.; Kowalczyk-Pecka, D. The Effect of Boswellia Serrata Resin Diet Supplementation on Production, Hematological, Biochemical and Immunological Parameters in Broiler Chickens. Animal 2017, 11, 1890-1898. [CrossRef]

193. Alvarez-Parrilla, E.; de la Rosa, L.A.; Amarowicz, R.; Shahidi, F. Antioxidant Activity of Fresh and Processed Jalapeño and Serrano Peppers. J. Agric. Food Chem. 2011, 59, 163-173. [CrossRef]

194. Zhuang, Y.; Chen, L.; Sun, L.; Cao, J. Bioactive Characteristics and Antioxidant Activities of Nine Peppers. J. Funct. Foods 2012, 4, 331-338. [CrossRef]

195. Santos, E.A.D.; Alvarez-Leite, J.I. Capsaicin: A Potential Therapy Adjuvant for Intestinal Bowel Disease. JDDD 2019, 2, 8-16. [CrossRef]

196. Kang, C.; Zhang, Y.; Zhu, X.; Liu, K.; Wang, X.; Chen, M.; Wang, J.; Chen, H.; Hui, S.; Huang, L.; et al. Healthy Subjects Differentially Respond to Dietary Capsaicin Correlating with Specific Gut Enterotypes. J. Clin. Endocrinol. Metab. 2016, 101, 4681-4689. [CrossRef] [PubMed]

197. Mason, J.R.; Maruniak, J.A. Behavioral and Physiological Effects of Capsaicin in Red-Winged Blackbirds. Pharmacol. Biochem. Behav. 1983, 19, 857-862. [CrossRef]

198. Geisthövel, E.; Ludwig, O.; Simon, E. Capsaicin Fails to Produce Disturbances of Autonomic Heat and Cold Defence in an Avian Species (Anas platyrhynchos). Pflugers. Arch. 1986, 406, 343-350. [CrossRef]

199. Szolcsányi, J.; Jancsó-Gábor, A. Sensory Effects of Capsaicin Congeners I. Relationship between Chemical Structure and PainProducing Potency of Pungent Agents. Arzneimittelforschung 1975, 25, 1877-1881.

200. Muley, B.; Khadabadi, S.; Banarase, N. Phytochemical Constituents and Pharmacological Activities of Calendula Officinalis Linn (Asteraceae): A Review. Trop. J. Pharm. Res. 2009, 8. [CrossRef]

201. Ukiya, M.; Akihisa, T.; Yasukawa, K.; Tokuda, H.; Suzuki, T.; Kimura, Y. Anti-Inflammatory, Anti-Tumor-Promoting, and Cytotoxic Activities of Constituents of Marigold (Calendula officinalis) Flowers. J. Nat. Prod. 2006, 69, 1692-1696. [CrossRef]

202. Yoshikawa, M.; Murakami, T.; Kishi, A.; Kageura, T.; Matsuda, H. Medicinal Flowers. III. Marigold. (1): Hypoglycemic, Gastric Emptying Inhibitory, and Gastroprotective Principles and New Oleanane-Type Triterpene Oligoglycosides, Calendasaponins A, B, C, and D, from Egyptian Calendula Officinalis. Chem. Pharm. Bull. 2001, 49, 863-870. [CrossRef]

203. Zitterl-Eglseer, K.; Sosa, S.; Jurenitsch, J.; Schubert-Zsilavecz, M.; Della Loggia, R.; Tubaro, A.; Bertoldi, M.; Franz, C. AntiOedematous Activities of the Main Triterpendiol Esters of Marigold (Calendula officinalis L.). J. Ethnopharmacol. 1997, 57, 139-144. [CrossRef]

204. Kalvatchev, Z.; Walder, R.; Garzaro, D. Anti-HIV Activity of Extracts from Calendula officinalis Flowers. Biomed. Pharmacother. 1997, 51, 176-180. [CrossRef]

205. Dall'Acqua, S.; Catanzaro, D.; Cocetta, V.; Igl, N.; Ragazzi, E.; Giron, M.C.; Cecconello, L.; Montopoli, M. Protective Effects of $\psi$ Taraxasterol 3-O-Myristate and Arnidiol 3-O-Myristate Isolated from Calendula officinalis on Epithelial Intestinal Barrier. Fitoterapia 2016, 109, 230-235. [CrossRef] [PubMed]

206. Foroutankhah, M.; Toghyani, M.; Landy, N. Evaluation of Calendula officinalis L. (Marigold) Flower as a Natural Growth Promoter in Comparison with an Antibiotic Growth Promoter on Growth Performance, Carcass Traits and Humoral Immune Responses of Broilers. Anim. Nutr. 2019, 5, 314-318. [CrossRef]

207. Rajput, N.; Naeem, M.; Ali, S.; Rui, Y.; Tian, W. Effect of Dietary Supplementation of Marigold Pigment on Immunity, Skin and Meat Color, and Growth Performance of Broiler Chickens. Braz. J. Poult. Sci. 2012, 4, 233-304. [CrossRef]

208. Page, J.E.; Nagel, J. Chapter Eight Biosynthesis of Terpenophenolic Metabolites in Hop and Cannabis. In Recent Advances in Phytochemistry; Elsevier: Amsterdam, The Netherlands, 2006.

209. Klein, T.W.; Cabral, G.A. Cannabinoid-Induced Immune Suppression and Modulation of Antigen-Presenting Cells. J. Neuroimmune Pharmacol. 2006, 1, 50-64. [CrossRef] 
210. Izzo, A.A.; Sharkey, K.A. Cannabinoids and the Gut: New Developments and Emerging Concepts. Pharmacol. Ther. 2010, 126, 21-38. [CrossRef] [PubMed]

211. Konieczka, P.; Szkopek, D.; Kinsner, M.; Fotschki, B.; Juśkiewicz, J.; Banach, J. Cannabis-Derived Cannabidiol and Nanoselenium Improve Gut Barrier Function and Affect Bacterial Enzyme Activity in Chickens Subjected to C. Perfringens Challenge. Vet. Res. 2020, 51, 141. [CrossRef]

212. Alhamoruni, A.; Lee, A.C.; Wright, K.L.; Larvin, M.; O'Sullivan, S.E. Pharmacological Effects of Cannabinoids on the Caco-2 Cell Culture Model of Intestinal Permeability. J. Pharmacol. Exp. Ther. 2010, 335, 92-102. [CrossRef]

213. Barceloux, D. Medical Toxicology of Natural Substances: Foods, Fungi, Medicinal Herbs, Plants and Venomous Animals; Wiley: Hoboken, NJ, USA, 2008.

214. Han, X.; Parker, T.L. Anti-Inflammatory Activity of Clove (Eugenia caryophyllata) Essential Oil in Human Dermal Fibroblasts. Pharm. Biol. 2017, 55, 1619-1622. [CrossRef]

215. Pirgozliev, V.; Rose, S.; Catherine, I.; Blanchard, A. Phytogenic Feed Additives Can Alleviate the Negative Impact of Necrotic Enteritis in Broilers. In Proceedings of the 6th International Conference on Poultry Intestinal Health, Rome, Italy, 3-5 April 2019.

216. Kumar, A.; Kheravii, S.K.; Ionescu, C.; Blanchard, A.; Barekatain, R.; Bajagai, Y.S.; Wu, S.-B. A Microencapsulated Mixture of Eugenol and Garlic Tincture Supplementation Mitigates the Effect of Necrotic Enteritis on Intestinal Integrity and Increases Goblet Cells in Broilers. Microorganisms 2021, 9, 1451. [CrossRef]

217. Ajdžanović, V.Z.; Medigović, I.M.; Pantelić, J.B.; Milošević, V.Lj. Soy Isoflavones and Cellular Mechanics. J. Bioenerg. Biomembr. 2014, 46, 99-107. [CrossRef]

218. Jiang, Z.Y.; Jiang, S.Q.; Lin, Y.C.; Xi, P.B.; Yu, D.Q.; Wu, T.X. Effects of Soybean Isoflavone on Growth Performance, Meat Quality, and Antioxidation in Male Broilers. Poult. Sci. 2007, 86, 1356-1362. [CrossRef] [PubMed]

219. Zhang, Y.-Z.; Shi, D.-X.; Zhou, B.-C.; Zeng, C.-K.; Pang, S.-J. Study on the Structure of C-Phycocyanin in Spirulina Platensis with Scanning Tunneling Microscope. Sheng Wu Hua Xue Yu Sheng Wu Wu Li Xue Bao 1997, 29, 521-525. [PubMed]

220. Messina, M.; Ho, S.; Alekel, D.L. Skeletal Benefits of Soy Isoflavones: A Review of the Clinical Trial and Epidemiologic Data. Curr. Opin. Clin. Nutr. Metab. Care 2004, 7, 649-658. [CrossRef] [PubMed]

221. Iqbal, Y.; Cottrell, J.J.; Suleria, H.A.R.; Dunshea, F.R. Gut Microbiota-Polyphenol Interactions in Chicken: A Review. Animals 2020, 10, 1391. [CrossRef]

222. Cassidy, A.; Brown, J.E.; Hawdon, A.; Faughnan, M.S.; King, L.J.; Millward, J.; Zimmer-Nechemias, L.; Wolfe, B.; Setchell, K.D.R. Factors Affecting the Bioavailability of Soy Isoflavones in Humans after Ingestion of Physiologically Relevant Levels from Different Soy Foods. J. Nutr. 2006, 136, 45-51. [CrossRef]

223. Azzam, M.M.; Jiang, S.; Chen, J.; Lin, X.; Gou, Z.; Fan, Q.; Wang, Y.; Li, L.; Jiang, Z. Effect of Soybean Isoflavones on Growth Performance, Immune Function, and Viral Protein 5 MRNA Expression in Broiler Chickens Challenged with Infectious Bursal Disease Virus. Animals 2019, 9, 247. [CrossRef]

224. Cassidy, A. Potential Risks and Benefits of Phytoestrogen-Rich Diets. Int. J. Vitam. Nutr. Res. 2003, 73, 120-126. [CrossRef]

225. Yousef, M.I.; Esmail, A.M.; Baghdadi, H.H. Effect of Isoflavones on Reproductive Performance, Testosterone Levels, Lipid Peroxidation, and Seminal Plasma Biochemistry of Male Rabbits. J. Environ. Sci. Health B 2004, 39, 819-833. [CrossRef]

226. Shin, J.-H.; Park, J.-M.; Bak, D.-J.; Jean, W.-M.; Song, J.-C.; Kim, S.-K.; An, B.-K.; Kang, C.-W.; Jung, W.-S.; Kim, J.-M. Effects of Germinated and Fermented Unmarketable Soybean on Laying Performance and Egg Quality in Laying Hens. Korean J. Food Sci. Anim. Resour. 2008, 28, 667-674. [CrossRef]

227. Shi, S.R.; Gu, H.; Chang, L.L.; Wang, Z.Y.; Tong, H.B.; Zou, J.M. Safety Evaluation of Daidzein in Laying Hens: Part I. Effects on Laying Performance, Clinical Blood Parameters, and Organs Development. Food Chem. Toxicol. 2013, 55, 684-688. [CrossRef]

228. Zhao, X.; Shao, T.; Wang, Y.Q.; Lu, X.L.; Luo, J.B.; Zhou, W.D. The Phytoestrogen Daidzein May Affect Reproductive Performance of Zhedong White Geese by Regulating Gene MRNA Levels in the HPG Axis. Br. Poult. Sci. 2013, 54, 252-258. [CrossRef] [PubMed]

229. Zhao, R.Q.; Zhou, Y.C.; Ni, Y.D.; Lu, L.Z.; Tao, Z.R.; Chen, W.H.; Chen, J. Effect of Daidzein on Egg-Laying Performance in Shaoxing Duck Breeders during Different Stages of the Egg Production Cycle. Br. Poult. Sci. 2005, 46, 175-181. [CrossRef] [PubMed]

230. Ni, Y.D.; Wu, J.; Tong, H.Y.; Huang, Y.B.; Lu, L.Z.; Grossmann, R.; Zhao, R.Q. Effect of Dietary Daidzein Supplementation on Egg Laying Rate Was Associated with the Change of Hepatic VTG-II MRNA Expression and Higher Antioxidant Activities during the Post-Peak Egg Laying Period of Broiler Breeders. Anim. Feed. Sci. Technol. 2012, 177, 116-123. [CrossRef]

231. Sahin, N.; Onderci, M.; Balci, T.A.; Cikim, G.; Sahin, K.; Kucuk, O. The Effect of Soy Isoflavones on Egg Quality and Bone Mineralisation during the Late Laying Period of Quail. Br. Poult. Sci. 2007, 48, 363-369. [CrossRef]

232. Kajiya, H.; Okabe, K.; Okamoto, F.; Tsuzuki, T.; Soeda, H. Protein Tyrosine Kinase Inhibitors Increase Cytosolic Calcium and Inhibit Actin Organization as Resorbing Activity in Rat Osteoclasts. J. Cell Physiol. 2000, 183, 83-90. [CrossRef]

233. Kosina, P.; Gregorova, J.; Gruz, J.; Vacek, J.; Kolar, M.; Vogel, M.; Roos, W.; Naumann, K.; Simanek, V.; Ulrichova, J. Phytochemical and Antimicrobial Characterization of Macleaya Cordata Herb. Fitoterapia 2010, 81, 1006-1012. [CrossRef]

234. Le, H.H.; Shakeri, M.; Suleria, H.A.R.; Zhao, W.; McQuade, R.M.; Phillips, D.J.; Vidacs, E.; Furness, J.B.; Dunshea, F.R.; ArtusoPonte, V.; et al. Betaine and Isoquinoline Alkaloids Protect against Heat Stress and Colonic Permeability in Growing Pigs. Antioxidants 2020, 9, 1024. [CrossRef] 
235. Vrublova, E.; Vostalova, J.; Ehrmann, J.; Palikova, I.; Vrbkova, J.; Vacek, J.; Cibicek, N.; Vecera, R.; Ulrichova, J.; Simanek, V. The Phytogenetic Feed Additive Sangrovit Modulates Dextran Sulfate Sodium-Induced Colitis in Rats. Vet. Med. 2010, 55, 610-618. [CrossRef]

236. Robbins, R.C.; Artuso-Ponte, V.C.; Moeser, A.J.; Morrow, W.E.M.; Spears, J.W.; Gebreyes, W.A. Effects of Quaternary Benzo(c)Phenanthridine Alkaloids on Growth Performance, Shedding of Organisms, and Gastrointestinal Tract Integrity in Pigs Inoculated with Multidrug-Resistant Salmonella Spp. Am. J. Vet. Res. 2013, 74, 1530-1535. [CrossRef]

237. Liu, W.; Zhai, Y.; Heng, X.; Che, F.Y.; Chen, W.; Sun, D.; Zhai, G. Oral Bioavailability of Curcumin: Problems and Advancements. J. Drug Target 2016, 24, 694-702. [CrossRef] [PubMed]

238. El, S.N.; Karakaya, S. Olive Tree (Olea europaea) Leaves: Potential Beneficial Effects on Human Health. Nutr. Rev. 2009, 67, 632-638. [CrossRef]

239. Talhaoui, N.; Vezza, T.; Gómez-Caravaca, A.M.; Fernández-Gutiérrez, A.; Gálvez, J.; Segura-Carretero, A. Phenolic Compounds and in Vitro Immunomodulatory Properties of Three Andalusian Olive Leaf Extracts. J. Funct. Foods 2016, 22, 270-277. [CrossRef]

240. Farràs, M.; Martinez-Gili, L.; Portune, K.; Arranz, S.; Frost, G.; Tondo, M.; Blanco-Vaca, F. Modulation of the Gut Microbiota by Olive Oil Phenolic Compounds: Implications for Lipid Metabolism, Immune System, and Obesity. Nutrients 2020, 12, 2200. [CrossRef]

241. Deiana, M.; Serra, G.; Corona, G. Modulation of Intestinal Epithelium Homeostasis by Extra Virgin Olive Oil Phenolic Compounds. Food Funct. 2018, 9, 4085-4099. [CrossRef] [PubMed]

242. Millman, J.; Okamoto, S.; Kimura, A.; Uema, T.; Higa, M.; Yonamine, M.; Namba, T.; Ogata, E.; Yamazaki, S.; Shimabukuro, M.; et al. Metabolically and Immunologically Beneficial Impact of Extra Virgin Olive and Flaxseed Oils on Composition of Gut Microbiota in Mice. Eur. J. Nutr. 2020, 59, 2411-2425. [CrossRef]

243. Şenay, S.; Dursen, Ü. The Use of Grape Seed-, Olive Leaf- and Pomegranate Peel-Extracts as Alternative Natural Antimicrobial Feed Additives in Broiler Diets; Verlag Eugen Ulmer: Stuttgart, Germany, 2016.

244. Herrero-Encinas, J.; Blanch, M.; Pastor, J.J.; Mereu, A.; Ipharraguerre, I.R.; Menoyo, D. Effects of a Bioactive Olive Pomace Extract from Olea Europaea on Growth Performance, Gut Function, and Intestinal Microbiota in Broiler Chickens. Poult. Sci. 2020, 99, 2-10. [CrossRef] [PubMed]

245. Liu, Z.; Wang, N.; Ma, Y.; Wen, D. Hydroxytyrosol Improves Obesity and Insulin Resistance by Modulating Gut Microbiota in High-Fat Diet-Induced Obese Mice. Front. Microbiol. 2019, 10, 390. [CrossRef]

246. Vezza, T.; Algieri, F.; Rodríguez-Nogales, A.; Garrido-Mesa, J.; Utrilla, M.P.; Talhaoui, N.; Gómez-Caravaca, A.M.; SeguraCarretero, A.; Rodríguez-Cabezas, M.E.; Monteleone, G.; et al. Immunomodulatory Properties of Olea Europaea Leaf Extract in Intestinal Inflammation. Mol. Nutr. Food Res. 2017, 61, 1601066. [CrossRef]

247. Hertog, M.G.L.; Hollman, P.C.H.; Katan, M.B. Content of Potentially Anticarcinogenic Flavonoids of 28 Vegetables and 9 Fruits Commonly Consumed in the Netherlands. J. Agric. Food Chem. 1992, 40, 2379-2383. [CrossRef]

248. Erlund, I. Review of the Flavonoids Quercetin, Hesperetin, and Naringenin. Dietary Sources, Bioactivities, Bioavailability, and Epidemiology. Nutr. Res. 2004, 24, 851-874. [CrossRef]

249. Tasdemir, D.; Lack, G.; Brun, R.; Rüedi, P.; Scapozza, L.; Perozzo, R. Inhibition of Plasmodium f Alciparum Fatty Acid Biosynthesis: Evaluation of FabG, FabZ, and FabI as Drug Targets for Flavonoids. J. Med. Chem. 2006, 49, 3345-3353. [CrossRef]

250. Wu, D.; Kong, Y.; Han, C.; Chen, J.; Hu, L.; Jiang, H.; Shen, X. D-Alanine:D-Alanine Ligase as a New Target for the Flavonoids Quercetin and Apigenin. Int. J. Antimicrob. Agents 2008, 32, 421-426. [CrossRef] [PubMed]

251. Abdel-Latif, M.A.; Elbestawy, A.R.; El-Far, A.H.; Noreldin, A.E.; Emam, M.; Baty, R.S.; Albadrani, G.M.; Abdel-Daim, M.M.; Abd El-Hamid, H.S. Quercetin Dietary Supplementation Advances Growth Performance, Gut Microbiota, and Intestinal MRNA Expression Genes in Broiler Chickens. Animals 2021, 11, 2302. [CrossRef] [PubMed]

252. Suzuki, T.; Hara, H. Quercetin Enhances Intestinal Barrier Function through the Assembly of Zonula [Corrected] Occludens-2, Occludin, and Claudin-1 and the Expression of Claudin-4 in Caco-2 Cells. J. Nutr. 2009, 139, 965-974. [CrossRef]

253. Amasheh, M.; Grotjohann, I.; Amasheh, S.; Fromm, A.; Söderholm, J.D.; Zeitz, M.; Fromm, M.; Schulzke, J.-D. Regulation of Mucosal Structure and Barrier Function in Rat Colon Exposed to Tumor Necrosis Factor Alpha and Interferon Gamma in Vitro: A Novel Model for Studying the Pathomechanisms of Inflammatory Bowel Disease Cytokines. Scand. J. Gastroenterol. 2009, 44, 1226-1235. [CrossRef]

254. Carrasco-Pozo, C.; Morales, P.; Gotteland, M. Polyphenols Protect the Epithelial Barrier Function of Caco-2 Cells Exposed to Indomethacin through the Modulation of Occludin and Zonula Occludens-1 Expression. J. Agric. Food Chem. 2013, 61, 5291-5297. [CrossRef]

255. Sim, G.-S.; Lee, B.-C.; Cho, H.S.; Lee, J.W.; Kim, J.-H.; Lee, D.-H.; Kim, J.-H.; Pyo, H.-B.; Moon, D.C.; Oh, K.-W.; et al. Structure Activity Relationship of Antioxidative Property of Flavonoids and Inhibitory Effect on Matrix Metalloproteinase Activity in UVA-Irradiated Human Dermal Fibroblast. Arch. Pharm. Res. 2007, 30, 290-298. [CrossRef]

256. Agullo, G.; Gamet-Payrastre, L.; Manenti, S.; Viala, C.; Rémésy, C.; Chap, H.; Payrastre, B. Relationship between Flavonoid Structure and Inhibition of Phosphatidylinositol 3-Kinase: A Comparison with Tyrosine Kinase and Protein Kinase C Inhibition. Biochem. Pharmacol. 1997, 53, 1649-1657. [CrossRef]

257. Fachini-Queiroz, F.C.; Kummer, R.; Estevão-Silva, C.F.; Carvalho, M.D.D.B.; Cunha, J.M.; Grespan, R.; Bersani-Amado, C.A.; Cuman, R.K.N. Effects of Thymol and Carvacrol, Constituents of Thymus vulgaris L. Essential Oil, on the Inflammatory Response. Evid. Based Complement Alternat. Med. 2012, 2012, 657026. [CrossRef] 
258. Hosseinzadeh, S.; Jafarikukhdan, A.; Hosseini, A.; Armand, R. The Application of Medicinal Plants in Traditional and Modern Medicine: A Review of Thymus vulgaris. IJCM 2015, 06, 635-642. [CrossRef]

259. Sakkas, H.; Papadopoulou, C. Antimicrobial Activity of Basil, Oregano, and Thyme Essential Oils. J. MicroBiol. Biotechnol. 2017, 27, 429-438. [CrossRef] [PubMed]

260. Yalçin, S.; Eser, H.; Onbaşilar, İ.; Yalçin, S. Effects of Dried Thyme (Thymus vulgaris L.) Leaves on Performance, Some Egg Quality Traits and Immunity in Laying Hens. Ank. Üniv. Vet. Fakültesi Derg. 2020, 67, 303-311. [CrossRef]

261. Turner, J.R. Molecular Basis of Epithelial Barrier Regulation: From Basic Mechanisms to Clinical Application. Am. J. Pathol. 2006, 169, 1901-1909. [CrossRef]

262. Placha, I.; Chrastinova, L.; Laukova, A.; Cobanova, K.; Takacova, J.; Strompfova, V.; Chrenkova, M.; Formelova, Z.; Faix, S. Effect of Thyme Oil on Small Intestine Integrity and Antioxidant Status, Phagocytic Activity and Gastrointestinal Microbiota in Rabbits. Acta Vet. Hung. 2013, 61, 197-208. [CrossRef] [PubMed]

263. Yoshino, K.; Higashi, N.; Koga, K. Antioxidant and Antiinflammatory Activities of Oregano Extract. J. Health Sci. 2006, 52, 169-173. [CrossRef]

264. Han, X.; Parker, T.L. Anti-Inflammatory, Tissue Remodeling, Immunomodulatory, and Anticancer Activities of Oregano (Origanum vulgare) Essential Oil in a Human Skin Disease Model. Biochim. Open 2017, 4, 73-77. [CrossRef] [PubMed]

265. Avola, R.; Granata, G.; Geraci, C.; Napoli, E.; Graziano, A.C.E.; Cardile, V. Oregano (Origanum vulgare L.) Essential Oil Provides Anti-Inflammatory Activity and Facilitates Wound Healing in a Human Keratinocytes Cell Model. Food Chem. Toxicol. 2020, 144, 111586. [CrossRef]

266. Du, E.; Wang, W.; Gan, L.; Li, Z.; Guo, S.; Guo, Y. Effects of Thymol and Carvacrol Supplementation on Intestinal Integrity and Immune Responses of Broiler Chickens Challenged with Clostridium perfringens. J. Anim. Sci. Biotechnol. 2016, 7, 19. [CrossRef]

267. Pham, V.H.; Kan, L.; Huang, J.; Geng, Y.; Zhen, W.; Guo, Y.; Abbas, W.; Wang, Z. Dietary Encapsulated Essential Oils and Organic Acids Mixture Improves Gut Health in Broiler Chickens Challenged with Necrotic Enteritis. J. Anim. Sci. Biotechnol. 2020, 11, 18. [CrossRef] [PubMed]

268. Hashemipour, H.; Kermanshahi, H.; Golian, A.; Veldkamp, T. Effect of Thymol and Carvacrol Feed Supplementation on Performance, Antioxidant Enzyme Activities, Fatty Acid Composition, Digestive Enzyme Activities, and Immune Response in Broiler Chickens. Poult. Sci. 2013, 92, 2059-2069. [CrossRef] [PubMed]

269. Zeng, Z.; Zhang, S.; Wang, H.; Piao, X. Essential Oil and Aromatic Plants as Feed Additives in Non-Ruminant Nutrition: A Review. J. Anim. Sci. Biotechnol. 2015, 6, 7. [CrossRef]

270. Feng, J.; Lu, M.; Wang, J.; Zhang, H.; Qiu, K.; Qi, G.; Wu, S. Dietary Oregano Essential Oil Supplementation Improves Intestinal Functions and Alters Gut Microbiota in Late-Phase Laying Hens. J. Anim. Sci. Biotechnol. 2021, 12, 72. [CrossRef] [PubMed]

271. Zhang, C.; Zhao, X.H.; Yang, L.; Chen, X.Y.; Jiang, R.S.; Jin, S.H.; Geng, Z.Y. Resveratrol Alleviates Heat Stress-Induced Impairment of Intestinal Morphology, Microflora, and Barrier Integrity in Broilers. Poult. Sci. 2017, 96, 4325-4332. [CrossRef] [PubMed]

272. Madeo, F.; Carmona-Gutierrez, D.; Hofer, S.J.; Kroemer, G. Caloric Restriction Mimetics against Age-Associated Disease: Targets, Mechanisms, and Therapeutic Potential. Cell Metab. 2019, 29, 592-610. [CrossRef] [PubMed]

273. Manna, S.K.; Mukhopadhyay, A.; Aggarwal, B.B. Resveratrol Suppresses TNF-Induced Activation of Nuclear Transcription Factors NF-Kappa B, Activator Protein-1, and Apoptosis: Potential Role of Reactive Oxygen Intermediates and Lipid Peroxidation. J. Immunol. 2000, 164, 6509-6519. [CrossRef]

274. Liu, L.L.; He, J.H.; Xie, H.B.; Yang, Y.S.; Li, J.C.; Zou, Y. Resveratrol Induces Antioxidant and Heat Shock Protein MRNA Expression in Response to Heat Stress in Black-Boned Chickens. Poult. Sci. 2014, 93, 54-62. [CrossRef]

275. Lagouge, M.; Argmann, C.; Gerhart-Hines, Z.; Meziane, H.; Lerin, C.; Daussin, F.; Messadeq, N.; Milne, J.; Lambert, P.; Elliott, P.; et al. Resveratrol Improves Mitochondrial Function and Protects against Metabolic Disease by Activating SIRT1 and PGC-1alpha. Cell 2006, 127, 1109-1122. [CrossRef]

276. Mayangsari, Y.; Suzuki, T. Resveratrol Enhances Intestinal Barrier Function by Ameliorating Barrier Disruption in Caco-2 Cell Monolayers. J. Funct. Foods 2018, 51, 39-46. [CrossRef]

277. Zhao, W.; Huang, X.; Han, X.; Hu, D.; Hu, X.; Li, Y.; Huang, P.; Yao, W. Resveratrol Suppresses Gut-Derived NLRP3 Inflammasome Partly through Stabilizing Mast Cells in a Rat Model. Mediat. Inflamm. 2018, 2018, 1-10. [CrossRef]

278. Zhang, C.; Yang, L.; Zhao, X.; Chen, X.; Wang, L.; Geng, Z. Effect of Dietary Resveratrol Supplementation on Meat Quality, Muscle Antioxidative Capacity and Mitochondrial Biogenesis of Broilers. J. Sci. Food Agric. 2018, 98, 1216-1221. [CrossRef] [PubMed]

279. Wang, C.; Zhao, F.; Li, Z.; Jin, X.; Chen, X.; Geng, Z.; Hu, H.; Zhang, C. Effects of Resveratrol on Growth Performance, Intestinal Development, and Antioxidant Status of Broilers under Heat Stress. Animals 2021, 11, 1427. [CrossRef] [PubMed]

280. Pan, M.-H.; Wu, J.-C.; Ho, C.-T.; Lai, C.-S. Antiobesity Molecular Mechanisms of Action: Resveratrol and Pterostilbene. Biofactors 2018, 44, 50-60. [CrossRef] [PubMed]

281. Cai, T.-T.; Ye, X.-L.; Li, R.-R.; Chen, H.; Wang, Y.-Y.; Yong, H.-J.; Pan, M.-L.; Lu, W.; Tang, Y.; Miao, H.; et al. Resveratrol Modulates the Gut Microbiota and Inflammation to Protect Against Diabetic Nephropathy in Mice. Front. Pharmacol. 2020, 11, 1249. [CrossRef] [PubMed]

282. Alrafas, H.R.; Busbee, P.B.; Nagarkatti, M.; Nagarkatti, P.S. Resveratrol Modulates the Gut Microbiota to Prevent Murine Colitis Development through Induction of Tregs and Suppression of Th17 Cells. J. Leukoc. Biol. 2019, 106, 467-480. [CrossRef] [PubMed]

283. Kocaadam, B.; Şanlier, N. Curcumin, an Active Component of Turmeric (Curcuma Longa), and Its Effects on Health. Crit. Rev. Food Sci. Nutr. 2017, 57, 2889-2895. [CrossRef] [PubMed] 
284. Tsuda, T. Curcumin as a Functional Food-Derived Factor: Degradation Products, Metabolites, Bioactivity, and Future Perspectives. Food Funct. 2018, 9, 705-714. [CrossRef] [PubMed]

285. Asai, A.; Miyazawa, T. Occurrence of Orally Administered Curcuminoid as Glucuronide and Glucuronide/Sulfate Conjugates in Rat Plasma. Life Sci. 2000, 67, 2785-2793. [CrossRef]

286. Ireson, C.R.; Jones, D.J.L.; Orr, S.; Coughtrie, M.W.H.; Boocock, D.J.; Williams, M.L.; Farmer, P.B.; Steward, W.P.; Gescher, A.J. Metabolism of the Cancer Chemopreventive Agent Curcumin in Human and Rat Intestine. Cancer Epidemiol. Biomark. Prev. 2002, 11, 105-111.

287. Pan, M.H.; Huang, T.M.; Lin, J.K. Biotransformation of Curcumin through Reduction and Glucuronidation in Mice. Drug Metab. Dispos. 1999, 27, 486-494.

288. Stohs, S.J.; Chen, O.; Ray, S.D.; Ji, J.; Bucci, L.R.; Preuss, H.G. Highly Bioavailable Forms of Curcumin and Promising Avenues for Curcumin-Based Research and Application: A Review. Molecules 2020, 25, 1397. [CrossRef]

289. Shehzad, A.; Wahid, F.; Lee, Y.S. Curcumin in Cancer Chemoprevention: Molecular Targets, Pharmacokinetics, Bioavailability, and Clinical Trials. Arch. Pharm. 2010, 343, 489-499. [CrossRef] [PubMed]

290. Han, H.-K. The Effects of Black Pepper on the Intestinal Absorption and Hepatic Metabolism of Drugs. Expert Opin. Drug Metab. Toxicol. 2011, 7, 721-729. [CrossRef] [PubMed]

291. Shaikh, J.; Ankola, D.D.; Beniwal, V.; Singh, D.; Kumar, M.N.V.R. Nanoparticle Encapsulation Improves Oral Bioavailability of Curcumin by at Least 9-Fold When Compared to Curcumin Administered with Piperine as Absorption Enhancer. Eur. J. Pharm. Sci. 2009, 37, 223-230. [CrossRef]

292. Itokawa, H.; Shi, Q.; Akiyama, T.; Morris-Natschke, S.L.; Lee, K.-H. Recent Advances in the Investigation of Curcuminoids. Chin. Med. 2008, 3, 11. [CrossRef] [PubMed]

293. Bao, W.; Li, K.; Rong, S.; Yao, P.; Hao, L.; Ying, C.; Zhang, X.; Nussler, A.; Liu, L. Curcumin Alleviates Ethanol-Induced Hepatocytes Oxidative Damage Involving Heme Oxygenase-1 Induction. J. Ethnopharmacol. 2010, 128, 549-553. [CrossRef] [PubMed]

294. Ma, T.Y.; Iwamoto, G.K.; Hoa, N.T.; Akotia, V.; Pedram, A.; Boivin, M.A.; Said, H.M. TNF-Alpha-Induced Increase in Intestinal Epithelial Tight Junction Permeability Requires NF-Kappa B Activation. Am. J. Physiol. Gastrointest. Liver Physiol. 2004, 286, G367-G376. [CrossRef]

295. Motterlini, R.; Foresti, R.; Bassi, R.; Green, C.J. Curcumin, an Antioxidant and Anti-Inflammatory Agent, Induces Heme Oxygenase-1 and Protects Endothelial Cells against Oxidative Stress. Free Radic. Biol. Med. 2000, 28, 1303-1312. [CrossRef]

296. McNally, S.J.; Harrison, E.M.; Ross, J.A.; Garden, O.J.; Wigmore, S.J. Curcumin Induces Heme Oxygenase 1 through Generation of Reactive Oxygen Species, P38 Activation and Phosphatase Inhibition. Int. J. Mol. Med. 2007, 19, 165-172. [CrossRef]

297. Huang, M.T.; Newmark, H.L.; Frenkel, K. Inhibitory Effects of Curcumin on Tumorigenesis in Mice. J. Cell Biochem. Suppl. 1997, 27, 26-34. [CrossRef]

298. Carmody, R.N.; Turnbaugh, P.J. Host-Microbial Interactions in the Metabolism of Therapeutic and Diet-Derived Xenobiotics. J. Clin. Invest. 2014, 124, 4173-4181. [CrossRef] [PubMed]

299. Jiang, H. Curcumin-Attenuated Trinitrobenzene Sulphonic Acid Induces Chronic Colitis by Inhibiting Expression of Cyclooxygenase-2. WJG 2006, 12, 3848. [CrossRef] [PubMed]

300. Scazzocchio, B.; Minghetti, L.; D'Archivio, M. Interaction between Gut Microbiota and Curcumin: A New Key of Understanding for the Health Effects of Curcumin. Nutrients 2020, 12, E2499. [CrossRef] [PubMed]

301. Peterson, C.T.; Vaughn, A.R.; Sharma, V.; Chopra, D.; Mills, P.J.; Peterson, S.N.; Sivamani, R.K. Effects of Turmeric and Curcumin Dietary Supplementation on Human Gut Microbiota: A Double-Blind, Randomized, Placebo-Controlled Pilot Study. J. Evid. Based Integr. Med. 2018, 23. [CrossRef]

302. Li, S.; Fu, C.; Zhao, Y.; He, J. Intervention with $\alpha$-Ketoglutarate Ameliorates Colitis-Related Colorectal Carcinoma via Modulation of the Gut Microbiome. BioMed Res. Int. 2019, 2019, 1-9. [CrossRef]

303. Wang, N.; Wang, G.; Hao, J.; Ma, J.; Wang, Y.; Jiang, X.; Jiang, H. Curcumin Ameliorates Hydrogen Peroxide-Induced Epithelial Barrier Disruption by Upregulating Heme Oxygenase-1 Expression in Human Intestinal Epithelial Cells. Dig. Dis. Sci. 2012, 57, 1792-1801. [CrossRef]

304. Leyva-Diaz, A.A.; Hernandez-Patlan, D.; Solis-Cruz, B.; Adhikari, B.; Kwon, Y.M.; Latorre, J.D.; Hernandez-Velasco, X.; FuenteMartinez, B.; Hargis, B.M.; Lopez-Arellano, R.; et al. Evaluation of Curcumin and Copper Acetate against Salmonella Typhimurium Infection, Intestinal Permeability, and Cecal Microbiota Composition in Broiler Chickens. J. Anim. Sci. Biotechnol. 2021, 12, 23. [CrossRef] 